\title{
Incidence, Antibiotic Susceptibility and Characterization of Vibrio parahaemolyticus Isolated from Seafood in Selangor, Malaysia
}

\author{
Vurmila Venggadasamy ${ }^{1}$, Loh Teng-Hern Tan ${ }^{2}$, Jodi Woan-Fei Law ${ }^{1}$, Hooi-Leng Ser ${ }^{1}$, \\ Vengadesh Letchumanan ${ }^{1 *}$, Priyia Pusparajah ${ }^{1 *}$ \\ Article History \\ Received: 29 July 2021; \\ Received in Revised Form: \\ 25 August 2021; \\ Accepted: 27 August 2021; \\ Available Online: 07 \\ September 2021 \\ ${ }^{1}$ Jeffrey Cheah School of Medicine and Health Sciences, Monash University, \\ Bandar Sunway, Subang Jaya, Selangor, 47500, Malaysia; \\ vven17@student.monash.edu (VV); jodi.law1@monash.edu (JW-FL); \\ ser.hooileng@monash.edu (H-LS) \\ ${ }^{2}$ Clinical School Johor Bahru, Jeffrey Cheah School of Medicine and Health \\ Sciences, Monash University Malaysia, Johor Bahru 80100, Malaysia; \\ loh.teng.hern@monash.edu (LT-HT) \\ *Corresponding author: Priyia Pusparajah, priyia.pusparajah@monash.edu \\ (PP); Vengadesh Letchumanan, vengadesh.letchumanan1@monash.edu \\ (VL)
}

Abstract: Vibrio parahaemolyticus is one of the major foodborne pathogens owing to its cause of infectious diseases such as gastroenteritis. These diseases are often associated with the consumption of contaminated seafood. This study aims to investigate the presence of $V$. parahaemolyticus, their virulence, antibiotic profiles, and plasmid profiles from 77 different kinds of shellfish samples collected from wet markets and supermarkets in Selangor, Malaysia. High densities of Vibrio species ( $>5 \log$ CFU/g) were found in 14/16 groups of shellfish. Among 77 presumptive $V$. parahaemolyticus isolates, $43(55.8 \%)$ were positive for the tox $R$ gene, confirming the identity of the isolates at the species level. However, none of the $V$. parahaemolyticus isolates harboured the virulence $t d h$ and $t r h$ genes. The antibiotic susceptibility of the $V$. parahaemolyticus isolates revealed that most of them were resistant to ampicillin (95.3\%), ampicillin-sulbactam (81.4\%), cefotaxime (37.2\%) and imipenem (23.3\%). The plasmid profiles of the V. parahaemolyticus isolates showed that $41.9 \%(18 / 43)$ possess at least one plasmid. Our results indicate the $V$. parahaemolyticus isolates are continuously exposed to various antibiotics in the environments, thus consuming the seafood carries a potential health risk to consumers. The antibiotic resistance conferred by the species necessitates an immediate plan to approach the usage of antibiotics differently.

Keywords: Vibrio parahaemolyticus; shellfish; prevalence; virulence; antibiotic resistance

\section{Introduction}

Seafood is a well-known source of omega-3 long-chain polyunsaturated fatty acids such as eicosapentaenoic acid and docosahexaenoic acid, protein, carnitine, vitamin A, B, D, 
and E, and minerals (i.e., magnesium, selenium, iodine, calcium, phosphorus, iron, and zinc $)^{[1-3]}$. These active compounds are shown to reduce the risk of preterm deliveries, triglyceride levels in type 2 diabetes mellitus, sarcopenia in the elderly and prostate cancerrelated mortalities ${ }^{[3-6]}$. The global consumption of fish has been increasing steadily at an annual rate of $3.1 \%$ from 1961 to 2017 . This is attributed to the steady increase in the production of these aquatic animals through aquaculture ${ }^{[7]}$. In 2018, the aquaculture industry produced 114.5 million tonnes of seafood consumed, in which Southeast Asia contributed to $17 \%$ of the total world production ${ }^{[7,8]}$. The aquaculture industry of Malaysia is a significant contributor to the overall production of seafood in Southeast Asia ${ }^{[9]}$. The increasing production of aquaculture products locally is attributed to the rise in seafood demand internationally and domestically ${ }^{[10]}$. Food and Agriculture Organization (FAO) of the United Nations reported that the domestic fish intake in Malaysia is $55.9 \mathrm{~kg}$ per capita, thrice as much as the global average of fish consumption ${ }^{[9]}$. This finding demonstrates the importance of seafood as a source of animal protein in Malaysia. Two of the most widely exported aquaculture products in Malaysia are cockles and shrimps ${ }^{[9]}$. The microbial spoilage of seafood can occur when contaminated water, sediments and sewage runoffs enter water bodies $^{[1,11-13]}$. In addition, once seafood is harvested, cross-contamination can also take place at any point during rearing, handling, preparing, processing, transporting, and storing ${ }^{[1,11,12]}$. Shellfish are prone to contamination by a plethora of organisms, resulting in shellfish-borne outbreaks ${ }^{[14]}$. Some of the most common foodborne pathogens include Vibrio species ${ }^{[15-19]}$, Salmonella species ${ }^{[20-25]}$, Escherichia coli, Listeria monocytogenes ${ }^{[26-30]}$, Plesiomonas shigelloides, hepatitis A virus, and calicivirus ${ }^{[14,31]}$.

Vibrio parahaemolyticus causes infectious diarrhoea associated with the consumption of raw or contaminated seafood ${ }^{[32-36]}$. The incubation period of the disease caused by this pathogen varies between literature. However, symptoms can occur as early as four hours post-infection ${ }^{[37,38]}$. V. parahaemolyticus causes gastroenteritis, which presents with watery diarrhoea, nausea, vomiting, abdominal pain, fever and chills ${ }^{[38]}$. The disease is self-limiting and lasts for approximately three days in healthy individuals ${ }^{[32-34]}$. The immunocompromised individuals may experience severe inflammatory diarrhoea, which could lead to septicaemia and death ${ }^{[34,39]}$. Pathogenic $V$. parahaemolyticus possess $t d h$ and trh genes that encode for thermostable direct haemolysin $(t d h)$ and thermostable direct haemolysin-related $(t r h)$, respectively, and is the primary virulence factors produced by $V$. parahaemolyticus ${ }^{[40,41]}$. These haemolysins are responsible for the enterotoxic, cytotoxic and haemolytic actions of the enteropathogen ${ }^{[33,34,42-46]}$. Environmental isolates of $V$. parahaemolyticus that do not possess $t d h$ and $t r h$ genes produce other virulence factors to exert pathogenicity. Studies have shown that non-tdh and non-trh producing $V$. parahaemolyticus can still maintain their 
enterotoxicity and cytotoxicity activities through other mechanisms, which includes but is not limited to thermolabile haemolysin (tlh), type III secretion systems (T3SSs) and type VI secretion system $(\mathrm{T} 6 \mathrm{SSs})^{[47-51]}$.

The widespread usage of antibiotics has exerted selection pressure on bacteria, leading to resistance against these therapeutic agents. Antibiotics are excessively used in the healthcare, agriculture, and aquaculture industries ${ }^{[52-54]}$. This has resulted in the Vibrio species developing multi-drug resistance against common antibiotics ${ }^{[55-57]}$. Generally, bacteria may possess intrinsic resistance genes in the chromosomes or acquire resistance genes via plasmids ${ }^{[55,58]}$. Mobile genetic elements such as plasmids are transferred to other bacteria via horizontal gene transfer or vertical gene transfer. The ubiquitous existence of Vibrio species in aquatic animals poses a risk to humans as multi-drug resistant Vibrio species can be transferred directly to humans via seafood consumption ${ }^{[1,59]}$. The risk is higher in Malaysia due to the growing aquaculture industry and high consumption of seafood locally ${ }^{[9,10]}$. To date, V. parahaemolyticus isolated from seafood have shown resistance to $\beta$ lactams (penicillin and ampicillin), third generation cephalosporins (cefotaxime and ceftazidime), second-generation cephalosporins (cefuroxime), first-generation cephalosporins (cephalothin), bacitracin, amikacin, and vancomycin ${ }^{[60-62]}$.

Frequent surveillance of the microbial status of seafood is crucial to monitor the prevalence of $V$. parahaemolyticus. The various virulence mechanisms exhibited by the pathogen contributes to the pathogenicity of bacteria, resulting in foodborne infections in human hosts. Besides that, the overuse and misuse of antibiotics have raised concerns regarding the multi-drug resistant strains of $V$. parahaemolyticus. Therefore, the focus of this study is to determine and characterise the prevalence, virulence, antibiotic resistance profile and plasmid profiles of $V$. parahaemolyticus isolated from seafood.

\section{Materials and Methods}

\subsection{Sampling}

This study included two types of bivalve mollusc (i.e., short-necked clam and blood clam) and crustacean (i.e., tiger prawn and Indian white shrimp). A total of 77 seafood samples were collected from two wet markets and two supermarkets in Selangor, Malaysia. Upon collection, the samples were kept in separate sterile sealed bags and transported to the laboratory for analysis ${ }^{[63]}$. 


\subsection{Enumeration of Presumptive Vibrio Species}

The enumeration of Vibrio species from seafood samples was conducted based on the Bacterial Analytical Manual of FDA and FAO/WHO Risk Assessment Tool for Vibrio parahaemolyticus and Vibrio vulnificus ${ }^{[63,64]} .10 \mathrm{~g}$ of the sample were weighed and placed in a sterile stomacher beg (Bagmixer® 400W, Interscience, France), and added with $90 \mathrm{~mL}$ of APW with $2 \% \mathrm{w} / \mathrm{v} \mathrm{NaCl}, \mathrm{pH} 8.5$. The samples are stomached for $90 \mathrm{~s}$. This produces the first $10^{-1}$ dilution $^{[65]}$. The subsequent tenfold dilutions (i.e., 1:10, 1:100, 1:1000, 1:10,000) were prepared by serial dilutions ${ }^{[66]}$.

HiCrome $^{\mathrm{TM}}$ Vibrio (HiMedia ${ }^{\mathrm{TM}}$, India) agar was used in the identification of Vibrio species in food samples ${ }^{[67]}$. The spread plate technique was employed for the enumeration of Vibrio species ${ }^{[68]}$. The HiCrome ${ }^{\mathrm{TM}}$ Vibrio (HiMedia ${ }^{\mathrm{TM}}$, India) agar plates were inoculated with $100 \mu \mathrm{L}$ of each dilution of the homogenate in triplicate. The agar plates were then incubated at $37^{\circ} \mathrm{C}$ for 18 hours. After that, the total number of Vibrio colonies were identified and enumerated. V. parahaemolyticus colonies are round, bluish-green, opaque and flat, whereas $V$. cholerae colonies are round, purple, opaque and flat on the HiCrome ${ }^{\mathrm{TM}}$ Vibrio (HiMedia $^{\mathrm{TM}}$, India) agar plates $^{[69]}$.

\subsection{Isolation of Presumptive Vibrio parahaemolyticus}

The isolation of Vibrio species from seafood samples was conducted based on the FDA Bacterial Analytical Manual and FAO/WHO Risk Assessment Tool ${ }^{[63,64]}$. The homogenate in the filter bags was incubated at $37^{\circ} \mathrm{C}$ for 18 hours to revitalise stressed bacterial cells. After that, $50 \mu \mathrm{L}$ of the homogenate was streaked onto the selective HiCrome $^{\mathrm{TM}}$ Vibrio (HiMedia $^{\mathrm{TM}}$, India) agar plates. The inoculated agar plates were then incubated at $37^{\circ} \mathrm{C}$ for 18 hours. Subsequently, presumptive $V$. parahaemolyticus colonies (based on the colony morphology) were picked and purified on Tryptic Soy Agar (TSA) (HiMedia $^{\mathrm{TM}}$, India) supplemented with $2 \% \mathrm{w} / \mathrm{v}$ sodium chloride ${ }^{[70,71]}$. The agar plates were then incubated at $37^{\circ} \mathrm{C}$ for 18 hours. Vibrios generally form large, cream coloured colonies on TSA plates ${ }^{[66]}$. The purified single colonies were then kept in semisolid nutrient agar until further analysis.

\subsection{Genomic DNA extraction}

The genomic DNA of presumptive $V$. parahaemolyticus was extracted by the direct boiled cell lysate method, as described in previous studies ${ }^{[61,72]}$. The $V$. parahaemolyticus colonies in the semisolid nutrient agars were revived in tryptic soy broth (TSB) (HiMedia, 
India) with $\mathrm{NaCl}(2 \% \mathrm{w} / \mathrm{v})$ and incubated in a shaker incubator at $200 \mathrm{RPM}$ and $37^{\circ} \mathrm{C}$ for 18 hours. One and a half millilitre of the overnight bacterial culture was transferred into microcentrifuge tubes and centrifuged for 5 minutes at 10,000 RPM. Centrifuging the bacterial suspension allows the concentration of the bacterial population in the suspension ${ }^{[72]}$.

The supernatant was discarded and the pellets were resuspended in $1 \mathrm{~mL}$ of sterile ultrapure water, vortexed and heated at $95^{\circ} \mathrm{C}$ for 7 minutes in a water bath. The application of heat causes the release of bacterial DNA strands from the cells ${ }^{[72]}$. The cell lysate was then cooled in ice for 5 minutes before centrifuging for 1 minute at 10,000 RPM. Lastly, the supernatant with the nucleic acid was pipetted into new $1.5 \mathrm{~mL}$ microcentrifuge tubes. The DNA samples were stored at $-20^{\circ} \mathrm{C}$ until further analysis.

\subsection{Identification of Vibrio parahaemolyticus using toxR-PCR}

A singleplex PCR assay targeting the toxR gene was employed in the molecular identification of the $V$. parahaemolyticus isolates $(n=77)$ at the species level (Table 6) ${ }^{[73]}$. The PCR assay was performed in a final volume of $20 \mu \mathrm{L}: 2 \mu \mathrm{L}$ of DNA template, $10 \mu \mathrm{L}$ of 2x Taq PLUS PCR Smart Mix 1 (SolGent ${ }^{\mathrm{TM}}$, Korea), $6 \mu \mathrm{L}$ of sterile ultrapure water, $1 \mu \mathrm{L}$ of primer toxR-F and toxR-R each. This process was completed using the SuperCycler: ThermalCycler (Kyratec, Australia) with the following thermal conditions: pre-denaturation of DNA at $95^{\circ} \mathrm{C}$ for 4 minutes, 35 cycles of denaturation at $94^{\circ} \mathrm{C}$ for 1 minute, annealing at $68^{\circ} \mathrm{C}$ for 1 minute and extension at $72^{\circ} \mathrm{C}$ for 30 seconds and final elongation at $72^{\circ} \mathrm{C}$ for 5 minutes $^{[74]}$. The PCR product was separated by electrophoresis in $1.5 \%$ agarose gel and visualised under a gel documentation system (ChemiDoc ${ }^{\mathrm{TM}}$ XRS, Bio-Rad, USA). Vibrio parahaemolyticus VP20 was employed as a positive control.

\subsection{Detection of Virulence Genes, thh and trh}

The toxR-positive isolates were subjected to a duplex PCR assay targeting the virulence genes, $t d h$ and $t r h$ (Table 1$)^{[43]}$. The PCR assay was performed in a final volume of $20 \mu \mathrm{L}: 2 \mu \mathrm{L}$ of DNA template, $10 \mu \mathrm{L}$ of $2 \mathrm{x}$ Taq PLUS PCR Smart Mix 1 (SolGent ${ }^{\mathrm{TM}}$, Korea), $4 \mu \mathrm{L}$ of sterile ultrapure water, $1 \mu \mathrm{L}$ of primer $t d h-\mathrm{F}, t d h-\mathrm{R}, t r h-\mathrm{F}$ and $t r h-\mathrm{R}$ each. This process was completed using the SuperCycler: ThermalCycler (Kyratec, Australia) with the following thermal conditions: pre-denaturation of DNA at $94^{\circ} \mathrm{C}$ for 3 minutes, 30 cycles of denaturation at $94^{\circ} \mathrm{C}$ for 1 minute, annealing at $58^{\circ} \mathrm{C}$ for 1 minute, extension at $72^{\circ} \mathrm{C}$ for 1 minute and final elongation at $72^{\circ} \mathrm{C}$ for 5 minutes ${ }^{[74]}$. The PCR product was separated by electrophoresis in 1.5\% agarose gel and visualised under a gel documentation system 
(ChemiDoc $^{\mathrm{TM}}$ XRS, Bio-Rad, USA). Vibrio parahaemolyticus VP20 was employed as a positive control.

Table 1. Primers used in the identification and virulence gene detection

\begin{tabular}{|c|c|c|c|}
\hline Primer & Primer sequence $\left(5^{\prime} \rightarrow 3^{\prime}\right)$ & $\begin{array}{c}\text { Amplicon } \\
\text { size (bp) }\end{array}$ & Reference \\
\hline tox $R-\mathrm{F}$ & GTCTTCTGACGCAATCGTTG & \multirow{2}{*}{368} & \multirow{2}{*}{ [75] } \\
\hline toxR $-\mathrm{R}$ & ATACGAGTGGTTGCTGTCATG & & \\
\hline$t d h-\mathrm{F}$ & GTAAAGGTCTCTGACTTTTGGAC & \multirow{2}{*}{269} & \multirow{2}{*}{ [76] } \\
\hline$t d h-\mathrm{R}$ & TGGAATAGAACCTTCATCTTCACC & & \\
\hline trh-F & TTGGCTTCGATATTTTCAGTATCT & \multirow[t]{2}{*}{500} & \multirow{2}{*}{ [76] } \\
\hline trh-R & CATAACAAACATATGCCCATTTCCG & & \\
\hline
\end{tabular}

\subsection{Antibiotic Susceptibility Test}

The $V$. parahaemolyticus isolates were examined for susceptibilities against 14 antibiotics (Table 2). These antibiotics were selected based on their importance in the clinical setting and aquaculture industry. Quinolones (nalidixic acid and levofloxacin) and thirdgeneration cephalosporin (cefotaxime and ceftazidime) are indicated in severe Vibriosis, whereas tetracycline is recommended in cholera ${ }^{[77-80]}$. The ampicillin-sulbactam covers bacterial infections that are resistant to ampicillin ${ }^{[81]}$. Carbapenem (imipenem) and aminoglycoside (amikacin, gentamicin and kanamycin) are broad-spectrum antibiotics used in infections caused by Gram-negative and Gram-positive bacteria ${ }^{[82-85]}$. The $V$. parahaemolyticus isolates were also tested against trimethoprim-sulfamethoxazole and chloramphenicol, which are used in Pneumocystis jirovecii pneumonia and eye infections resulting from methicillin-resistant Staphylococcus aureus (MRSA), respectively ${ }^{[86,87]}$. On the other hand, oxytetracycline is an important drug in the aquaculture industry ${ }^{[88]}$.

The isolates were subjected to the antibiotic susceptibility test by the Kirby disc diffusion method ${ }^{[89]}$. This method has been employed in several studies investigating the antibiotic sensitivity in $V$. parahaemolyticus isolated from food samples ${ }^{[90,91]}$. All the isolates were revived in Tryptic Soy Broth (TSB) (HiMedia, India) supplemented with $\mathrm{NaCl}$ (2\% $\mathrm{w} / \mathrm{v}$ ) and shaken at $37^{\circ} \mathrm{C}$ for 18 hours at $200 \mathrm{RPM}$. After the incubation, $100 \mu \mathrm{L}$ of the suspension was swabbed uniformly onto the surface of the Mueller-Hinton (HiMedia, India) agar plate with a sterile cotton swab. The agar plates were then incubated at $37^{\circ} \mathrm{C}$ for 18 hours. The diameter of the inhibition zones was measured and interpreted according to the 
guidelines provided by Clinical and Laboratory Standards Institute M45 ${ }^{[92]}$. The MAR index was calculated using the formula below, which was initially developed by Krumperman ${ }^{[93]}$. Multiple antibiotic resistance $(M A R)=\frac{a}{b}=\frac{\text { Number of antibiotics that the isolates are resistant to }}{\text { Total number of antibiotics the isolates are exposed to }}$

Table 2. The list of antibiotics tested in this study ${ }^{[94-96]}$

\begin{tabular}{|c|c|c|}
\hline Class of antibiotics & Antibiotics & Concentration $(\mu \mathrm{g})$ \\
\hline Penicillin & Ampicillin & 10 \\
\hline$\beta$-lactamase inhibitor & Ampicillin-sulbactam & 30 \\
\hline \multirow{2}{*}{ Third-generation cephalosporin } & Cefotaxime & 30 \\
\hline & Ceftazidime & 30 \\
\hline Carbapenem & Imipenem & 10 \\
\hline \multirow{3}{*}{ Aminoglycoside } & Amikacin & 30 \\
\hline & Gentamicin & 30 \\
\hline & Kanamycin & 30 \\
\hline Dihydrofolate reductase inhibitor & $\begin{array}{l}\text { Trimethoprim- } \\
\text { sulfamethoxazole }\end{array}$ & 25 \\
\hline \multirow{2}{*}{ Tetracycline } & Tetracycline & 30 \\
\hline & Oxytetracycline & 30 \\
\hline \multirow{2}{*}{ Quinolone } & Nalidixic acid & 30 \\
\hline & Levofloxacin & 5 \\
\hline Anti-50S antimicrobial & Chloramphenicol & 30 \\
\hline
\end{tabular}

\subsection{Plasmid Profiling}

The bacterial isolates were revived in Tryptic Soy Broth (TSB) (HiMedia, India) supplemented with $\mathrm{NaCl}(2 \% \mathrm{w} / \mathrm{v})$ and shaken at $37^{\circ} \mathrm{C}$ in a shaker incubator (200 RPM) for 18 hours. $1.5 \mathrm{~mL}$ of the suspension were transferred into a new microcentrifuge tube, and this was used for the plasmid extraction using the GF-1 Plasmid DNA Extraction Kit (Vivantis Technologies, Malaysia). The plasmid DNA was separated by gel electrophoresis in $1.0 \%$ agarose gel and visualised under UV light with a gel documentation system (ChemiDoc ${ }^{\mathrm{TM}}$ XRS, Bio-Rad, USA). 


\subsection{Statistical Analysis}

The analysis of the data was conducted using the statistical analysis software, IBM ${ }^{\circledR}$ SPSS ${ }^{\circledR}$ Statistics version 26. A one-way ANOVA test was performed to determine if the difference between the mean Vibrio count in the four types of shellfish samples were statistically significant. Besides that, a chi-squared test was used to determine whether the differences in the prevalence of Vibrio parahaemolyticus in seafood from wet markets and supermarkets were statistically different. Another chi-squared test was employed to study the relationship between different types of establishments and the number of $V$. parahaemolyticus isolates with a MAR index of more than 0.2. A difference was considered statistically significant when $p<0.05$.

\section{Results}

\subsection{Microbial Load of total Vibrio species}

A total of 77 shellfish comprising of short-necked clam (Paratapes undulatus) ( $n=$ 19), blood clam (Tegillarca granosa) $(n=20)$, tiger prawn (Penaeus monodon) $(n=19)$ and Indian white shrimp (Penaeus indicus) $(n=19)$ were sampled from two wet markets and two supermarkets in Selangor, Malaysia.

The mean Vibrio count is calculated according to the sample type from the respective sampling sites (Table 3). Out of 16 groups of shellfish samples, 14 groups were contaminated with more than $5 \log$ CFU/g of Vibrio species, which is the minimum bacterial load required to cause symptoms of Vibriosis in human hosts ${ }^{[61]}$. The only group of samples with a mean Vibrio count lower than the infectivity limit are tiger prawns from Wet market 1 and Indian white shrimps from Supermarket 2. Overall, the mean density of Vibrio species in all the shellfish samples ranges from $4.66 \pm 0.40$ to $8.95 \pm 0.00 \mathrm{log} \mathrm{CFU} / \mathrm{g}$. The highest count is seen in short-necked clams from Wet market 2, followed by blood clams from Wet market 1 $(6.06 \pm 0.01 \log \mathrm{CFU} / \mathrm{g})$ and short-necked clams from Wet market $1(5.98 \pm 0.04)$. The lowest Vibrio count is detected in tiger prawns from Wet market 1.

The highest mean Vibrio count in each seafood sample type from all the markets, 6.52 $\log \mathrm{CFU} / \mathrm{g}$, is seen in short-necked clam samples, followed by $5.77 \log$ CFU/g in blood clams, $5.50 \log \mathrm{CFU} / \mathrm{g}$ in Indian white shrimps and $5.34 \mathrm{log} \mathrm{CFU} / \mathrm{g}$ in tiger prawns. One-way ANOVA test performed showed a significant difference between the mean of Vibrio count in the four types of shellfish $(p=0.005)$. Mean Vibrio count in Indian white shrimps is significantly lower than short-necked clams $(-1.03,95 \% \mathrm{CI}=-1.95--0.10, p=0.022)$. Besides that, tiger prawns also have mean Vibrio count that is significantly lower than shortnecked clams $(-1.19,95 \% \mathrm{CI}=-2.11--0.27, p=0.005)$. However, the mean Vibrio count was not statistical significant between the blood clam and short-necked clam samples $(-0.76$, $95 \% \mathrm{CI}=-1.68-0.17, p=0.005)$. 
Table 3. Mean total Vibrio species count listed according to the type of seafood samples and sampling sites.

\begin{tabular}{|c|c|c|c|c|}
\hline \multirow[t]{2}{*}{ Sample } & \multicolumn{4}{|c|}{$\begin{array}{c}\text { Mean of total Vibrio count }(\log \text { CFU/g) } \\
\text { Mean } \pm \text { Standard deviation }\end{array}$} \\
\hline & Wet market 1 & Wet market 2 & Supermarket 1 & Supermarket 2 \\
\hline $\begin{array}{l}\text { Paratapes undulatus } \\
\text { (Short-necked clam) }\end{array}$ & $5.98 \pm 0.04$ & $8.95 \pm 0.00$ & $5.71 \pm 0.17$ & $5.46 \pm 0.08$ \\
\hline $\begin{array}{l}\text { Tegillarca granosa } \\
\text { (Blood clam) }\end{array}$ & $6.06 \pm 0.01$ & $5.75 \pm 0.02$ & $5.42 \pm 0.03$ & $5.84 \pm 0.03$ \\
\hline $\begin{array}{l}\text { Penaeus monodon } \\
\text { (Tiger prawn) }\end{array}$ & $4.66 \pm 0.40$ & $5.79 \pm 0.05$ & $5.21 \pm 0.08$ & $5.67 \pm 0.05$ \\
\hline $\begin{array}{l}\text { Penaeus indicus } \\
\text { (Indian white shrimp) }\end{array}$ & $5.41 \pm 0.11$ & $5.74 \pm 0.05$ & $4.89 \pm 0.21$ & $5.95 \pm 0.04$ \\
\hline
\end{tabular}

\subsection{Molecular Identification of Vibrio parahaemolyticus}

The PCR assay revealed positive amplification of the toxR gene with $368 \mathrm{bp}$ amplicon band in 55.8\% (43/77) of the presumptive Vibrio parahaemolyticus isolates (Table 4). The incidence of Vibrio parahaemolyticus in the shellfish samples was highest in samples collected from Supermarket 1 at 70.0\% (14/20), followed by Wet market 1 at $61.0 \%(11 / 18)$. Supermarket 1 presented the lowest prevalence of $V$. parahaemolyticus at 35\% (7/20). Among the samples, V. parahaemolyticus is most prevalent in tiger prawn $78.9 \%(15 / 19)$, followed by Indian white shrimp 68.4\% (13/19), blood clam 45.0\% (9/20) and short-necked clam 31.6\% (6/19) (Table 2). The results of a chi-squared test performed showed no significant association between the number of toxR-positive $V$. parahaemolyticus isolates in shellfish from wet markets and supermarkets $(51.2 \%$ vs. $48.8 \%, p=0.539)$. None of the 43 $V$. parahaemolyticus isolates harboured the thermostable direct haemolysin (tdh) and thermostable direct haemolysin-related (trh) virulence genes. 
Table 4. Prevalence of Vibrio parahaemolyticus in the shellfish samples

\begin{tabular}{|c|c|c|c|c|c|c|c|c|c|c|}
\hline \multirow{2}{*}{$\begin{array}{c}\text { Sites } \\
\text { Type of } \\
\text { shellfish }\end{array}$} & \multicolumn{2}{|c|}{ Wet market 1} & \multicolumn{2}{|c|}{ Wet market 2} & \multicolumn{2}{|c|}{ Supermarket 1} & \multicolumn{2}{|c|}{ Supermarket 2} & \multicolumn{2}{|c|}{ Overall } \\
\hline & $\begin{array}{c}\text { Total } \\
\text { no. of } \\
\text { isolates }\end{array}$ & $\begin{array}{c}\text { toxR- } \\
\text { positive } \\
(\%)\end{array}$ & $\begin{array}{c}\text { Total } \\
\text { no. of } \\
\text { isolates }\end{array}$ & $\begin{array}{c}\text { toxR- } \\
\text { positive } \\
(\%)\end{array}$ & $\begin{array}{c}\text { Total } \\
\text { no. of } \\
\text { isolates }\end{array}$ & $\begin{array}{c}\text { toxR- } \\
\text { positive } \\
(\%)\end{array}$ & $\begin{array}{c}\text { Total } \\
\text { no. of } \\
\text { isolates }\end{array}$ & $\begin{array}{c}\text { toxR- } \\
\text { positive } \\
(\%)\end{array}$ & $\begin{array}{c}\text { Total } \\
\text { no. of } \\
\text { isolates }\end{array}$ & $\begin{array}{c}\text { toxR- } \\
\text { positive } \\
(\%)\end{array}$ \\
\hline $\begin{array}{l}\text { Paratapes } \\
\text { undulatus } \\
\text { (Short- } \\
\text { necked } \\
\text { clam) }\end{array}$ & 5 & $\begin{array}{c}1 \\
(20.0)\end{array}$ & 4 & $\begin{array}{c}1 \\
(25.0)\end{array}$ & 5 & $\begin{array}{c}3 \\
(60.0)\end{array}$ & 5 & $\begin{array}{c}1 \\
(20.0)\end{array}$ & 19 & $\begin{array}{c}6 \\
(31.6)\end{array}$ \\
\hline $\begin{array}{l}\text { Tegillarca } \\
\text { granosa } \\
\text { (Blood } \\
\text { clam) } \\
\end{array}$ & 5 & $\begin{array}{c}4 \\
(80.0)\end{array}$ & 5 & $\begin{array}{c}2 \\
(40.0)\end{array}$ & 5 & $\begin{array}{c}0 \\
(0.0)\end{array}$ & 5 & $\begin{array}{c}3 \\
(60.0)\end{array}$ & 20 & $\begin{array}{c}9 \\
(45.0)\end{array}$ \\
\hline $\begin{array}{l}\text { Penaeus } \\
\text { monodon } \\
\text { (Tiger } \\
\text { prawn) } \\
\end{array}$ & 3 & $\begin{array}{c}3 \\
(100)\end{array}$ & 6 & $\begin{array}{c}4 \\
(67.0)\end{array}$ & 5 & $\begin{array}{c}3 \\
(60.0)\end{array}$ & 5 & $\begin{array}{c}5 \\
(100)\end{array}$ & 19 & $\begin{array}{c}15 \\
(78.9)\end{array}$ \\
\hline $\begin{array}{l}\text { Penaeus } \\
\text { indicus } \\
\text { (Indian } \\
\text { white } \\
\text { shrimp) }\end{array}$ & 5 & $\begin{array}{c}3 \\
(60.0)\end{array}$ & 4 & $\begin{array}{c}4 \\
(100)\end{array}$ & 5 & $\begin{array}{c}1 \\
(20.0)\end{array}$ & 5 & $\begin{array}{c}5 \\
(100)\end{array}$ & 19 & $\begin{array}{c}13 \\
(68.4)\end{array}$ \\
\hline Total & 18 & $\begin{array}{c}11 \\
(61.0)\end{array}$ & 19 & $\begin{array}{c}11 \\
(58.0)\end{array}$ & 20 & $\begin{array}{c}7 \\
(35.0) \\
\end{array}$ & 20 & $\begin{array}{c}14 \\
(70.0)\end{array}$ & 77 & $\begin{array}{c}43 \\
(55.8)\end{array}$ \\
\hline
\end{tabular}

\subsection{Antibiotic Susceptibility Test and Multiple Antibiotic Resistance (MAR) Indices}

The antibiotic resistance profiles of all $43 \mathrm{~V}$. parahaemolyticus isolates are summarised in Table 5. A vast majority of the bacterial isolates were resistant to ampicillin (95.3\%). Similarly, resistance towards the combination antibiotic, ampicillin-sulbactam was also high $(81.4 \%)$. The antibiotic resistance profile of the $V$. parahaemolyticus isolates towards third-generation cephalosporins showed mixed results. There was nearly an equal distribution between isolates that were resistant (37.2\%) to cefotaxime and sensitive $(34.5 \%)$ towards the said drug. In contrast, most isolates were susceptible to ceftazidime $(55.8 \%)$, with a high proportion of the isolates showing intermediate resistance towards this antibiotic (37.2\%). Although most of the V. parahaemolyticus isolates (76.7\%) were susceptible to the carbapenem antibiotic, imipenem, $23.3 \%$ (10/43) were resistant to this antibiotic. This 
finding is worrying because carbapenems are broad-spectrum antibiotics commonly used as the last line of drug in Gram-negative and Gram-positive bacterial infections ${ }^{[82,83]}$.

Table 5. Antibiotic resistance profile of the Vibrio parahaemolyticus isolated from the shellfish.

\begin{tabular}{|c|c|c|c|}
\hline Antibiotics & $\begin{array}{c}\text { Resistant } \\
\text { n (\%) }\end{array}$ & $\begin{array}{c}\text { Intermediate } \\
\text { n }(\%)\end{array}$ & $\begin{array}{c}\text { Sensitive } \\
\mathrm{n}(\%)\end{array}$ \\
\hline Ampicillin $10 \mu \mathrm{g}$ & $41(95.3)$ & $0(0.0)$ & $2(4.7)$ \\
\hline Ampicillin-sulbactam $30 \mu \mathrm{g}$ & $35(81.4)$ & $5(11.6)$ & $3(7.0)$ \\
\hline Cefotaxime $30 \mu \mathrm{g}$ & $16(37.2)$ & $12(27.9)$ & $15(34.9)$ \\
\hline Ceftazidime $30 \mu \mathrm{g}$ & $3(7.0)$ & $16(37.2)$ & $24(55.8)$ \\
\hline Imipenem $10 \mu \mathrm{g}$ & $10(23.3)$ & $0(0.0)$ & $33(76.7)$ \\
\hline Amikacin $30 \mu \mathrm{g}$ & $1(2.3)$ & $3(7.0)$ & $39(90.7)$ \\
\hline Gentamicin $30 \mu \mathrm{g}$ & $2(4.7)$ & $1(2.3)$ & $40(93.0)$ \\
\hline Kanamycin $30 \mu \mathrm{g}$ & $4(9.3)$ & $9(20.9)$ & $30(69.8)$ \\
\hline Trimethoprim-sulfamethoxazole $25 \mu \mathrm{g}$ & $0(0.0)$ & $0(0.0)$ & $43(100.0)$ \\
\hline Tetracycline $30 \mu \mathrm{g}$ & $8(18.6)$ & $3(7.0)$ & $32(74.4)$ \\
\hline Oxytetracycline $30 \mu \mathrm{g}$ & $7(16.3)$ & $1(2.3)$ & $35(81.4)$ \\
\hline Nalidixic acid $30 \mu \mathrm{g}$ & $1(2.3)$ & $1(2.3)$ & $41(95.3)$ \\
\hline Levofloxacin $5 \mu \mathrm{g}$ & $1(2.3)$ & $0(0.0)$ & $42(97.7)$ \\
\hline Chlorampenicol $30 \mu \mathrm{g}$ & $0(0.0)$ & $0(0.0)$ & $43(100.0)$ \\
\hline
\end{tabular}

In contrast, the $V$. parahaemolyticus isolates were highly susceptible to quinolones (levofloxacin, 97.7\%; nalidixic acid, 95.3\%), aminoglycosides (gentamicin, 93\%; amikacin, 90.7\%; kanamycin, 69.8\%) and tetracyclines (oxytetracycline, $81.4 \%$; tetracycline, $74.4 \%$ ). Unsurprisingly, all the isolates were sensitive towards trimethoprim-sulfamethoxazole and chloramphenicol.

The isolates exhibited MAR indices ranging from 0.07 to 0.36 . The highest MAR index (0.36) was seen in $5 / 43(7.0 \%)$ bacterial isolates. These isolates were resistant to penicillin, beta-lactamase inhibitors, third-generation cephalosporins, carbapenems and, either quinolones or tetracyclines. The highest frequency of the MAR index was 0.21 , followed by $0.29 .37 .2 \%$ (16/43) of the $V$. parahaemolyticus isolates exhibited a MAR index of 0.21 , whereas $25.9 \%$ (11/43) had a MAR index of 0.29. Among all $43 \mathrm{~V}$. parahaemolyticus isolates, only one (2.3\%) did not exhibit MAR as it was sensitive to all the antibiotics included in the study. Interestingly, all $10 \mathrm{~V}$. parahaemolyticus isolates that were resistant to 
imipenem demonstrated MAR indices ranging from 0.21 to 0.36 , which is the highest MAR index reported in this study.

Bacterial isolate with a MAR index of more than 0.2 connotes the origin of the isolate from a high-risk source of contamination. This means that a particular strain of Vibrio parahaemolyticus was exposed to an increased number of antimicrobials ${ }^{[97,98]}$. In the present study, 30/43 V. parahaemolyticus isolates had a MAR index of more than 0.2. Cumulatively, this was expressed by $69.8 \%$ of the bacterial isolates which were resistant to 3 to 5 different antibiotics tested. Of the $30 \mathrm{~V}$. parahaemolyticus isolates with a MAR index exceeding 0.2 , an equal number of bacterial strains were isolated from wet market and supermarket samples. A chi-squared test was performed to study the relationship between different types of establishments and the risk of contamination. The analysis shows that there was no significant difference in the risk of contamination among different sources of shellfish (50\% vs. 50\%; $p$ $=0.054)$.

\subsection{Plasmid Profiles of Vibrio parahaemolyticus}

All 43 toxR-positive $V$. parahaemolyticus isolates were subjected to plasmid profiling and the profiles are illustrated in Table 6. Among all the $V$. parahaemolyticus isolates, 18 (41.9\%) isolates harboured at least one plasmid, whereas the majority did not possess any plasmids $(25 / 43 ; 58.1 \%)$. Interestingly, all the isolates without plasmids (excluding VV34) were resistant to at least 1 antibiotic with MAR indices ranging from 0.07 to 0.29 (Table 7).

Cumulatively, the number of plasmids in the $V$. parahaemolyticus isolates ranges from one to four, whereby $20.9 \%$ (9/43), $14.0 \%$ (6/43), and $4.7 \%(2 / 23)$ of the isolates had one, two and three plasmids, respectively. Only one (2.3\%) strain of $V$. parahaemolyticus harboured four plasmid DNA bands with molecular weights of $1.5 \mathrm{~kb}, 5.2 \mathrm{~kb}, 7 \mathrm{~kb}$ and above $10 \mathrm{~kb}$. This $V$. parahaemolyticus isolate, VV40, was resistant to four antibiotics which are ampicillin, ampicillin-sulbactam, cefotaxime and imipenem. In contrast, the VV34 strain, which was susceptible to all the antibiotics tested, did not harbour any plasmids.

The molecular weight of the plasmids that reside in the $V$. parahaemolyticus isolates ranges from $1 \mathrm{~kb}$ to more than $10 \mathrm{~kb}$. The plasmid DNA bands in each strain of bacteria were categorised according to the number of plasmids and plasmid sizes. With that, 14 different plasmid patterns were encountered among the $V$. parahaemolyticus isolates. The most common plasmid pattern seen is 1.1 , which refers to the possession of one plasmid with a size of more than $10 \mathrm{~kb}$. This pattern has been identified in 4/43 (9.3\%) V. parahaemolyticus isolates. 
Besides that, VV09, VV30 and VV37, which were resistant to five out of 14 antibiotics tested, had relatively bigger plasmids. VV37 has only one plasmid that is more than $10 \mathrm{~kb}$ but is resistant to five different antibiotics, namely, ampicillin, ampicillinsulbactam, cefotaxime, imipenem, and tetracycline. VV30 has plasmids with the molecular weight of more than $10 \mathrm{~kb}$ and $10 \mathrm{~kb}$, whereas VV09 has $10 \mathrm{~kb}$ - and 2kb-sized plasmids. Strikingly, 9 out of 10 (90\%) Vibrio parahaemolyticus isolates that were resistant to imipenem had one to four plasmids, sizes ranging from $1.5 \mathrm{~kb}$ to more than $10 \mathrm{~kb}$. VV38 is the only bacterial strain that was resistant to imipenem but did not harbour any plasmids.

Table 6. Plasmid profiles of the Vibrio parahaemolyticus isolates from shellfish samples

\begin{tabular}{|c|c|c|c|c|}
\hline $\begin{array}{l}\text { Number of } \\
\text { plasmids }\end{array}$ & $\begin{array}{l}\text { Plasmid } \\
\text { pattern }\end{array}$ & $\begin{array}{l}\text { Plasmid } \\
\text { size }(k b)\end{array}$ & $\begin{array}{l}\text { Number of } \\
\text { isolates (\%) }\end{array}$ & Vibrio parahaemolyticus isolates \\
\hline 0 & & & $25(58.1)$ & $\begin{array}{l}\text { VV02, VV10, VV11, VV12, VV21, VV22, } \\
\text { VV23, VV25, VV26, VV27, VV34, VV38, } \\
\text { VV39, VV41, VV42, VV43, VV52, VV56, } \\
\text { VV57, VV58, VV65, VV68, VV69, VV70, VV75 }\end{array}$ \\
\hline \multirow{5}{*}{1} & 1.1 & $>10$ & $4(9.3)$ & VV37, VV45, VV48, VV49 \\
\hline & 1.2 & 10 & $2(4.7)$ & VV29, VV67 \\
\hline & 1.3 & 7 & $1(2.3)$ & VV19 \\
\hline & 1.4 & 5.2 & $1(2.3)$ & VV64 \\
\hline & 1.5 & 1.5 & $1(2.3)$ & VV71 \\
\hline \multirow{6}{*}{2} & 2.1 & $>10,10$ & $1(2.3)$ & VV30 \\
\hline & 2.2 & 10,4 & $1(2.3)$ & VV14 \\
\hline & 2.3 & 10,2 & $1(2.3)$ & VV09 \\
\hline & 2.4 & $7,6.2$ & $1(2.3)$ & VV07 \\
\hline & 2.5 & 7,4 & $1(2.3)$ & VV24 \\
\hline & 2.6 & $6.2,5.2$ & $1(2.3)$ & VV01 \\
\hline \multirow[t]{2}{*}{3} & 3.1 & $\begin{array}{c}10,6.2 \\
2.5\end{array}$ & $1(2.3)$ & VV08 \\
\hline & 3.2 & $10,5.2,2$ & $1(2.3)$ & VV35 \\
\hline 4 & 4.1 & $\begin{array}{l}>10,7 \\
5.2,1.5\end{array}$ & $1(2.3)$ & VV40 \\
\hline
\end{tabular}


Table 7. Plasmid profiles and antibiograms of Vibrio parahaemolyticus isolates.

\begin{tabular}{|c|c|c|c|c|c|}
\hline $\begin{array}{l}\text { Number } \\
\text { of } \\
\text { plasmids }\end{array}$ & $\begin{array}{l}\text { Plasmid } \\
\text { pattern }\end{array}$ & $\begin{array}{l}\text { Plasmid } \\
\text { size }(k b)\end{array}$ & $\begin{array}{l}\text { MAR } \\
\text { index }\end{array}$ & Antibiogram & Isolates \\
\hline \multirow{17}{*}{0} & & & 0.0 & & VV34 \\
\hline & & & 0.07 & AMP & VV22, VV39 \\
\hline & & & 0.14 & AMP/SAM & $\begin{array}{l}\text { VV02, VV26, VV52, } \\
\text { VV57, VV65 }\end{array}$ \\
\hline & & & 0.14 & AMP/OT & VV43 \\
\hline & & & 0.21 & AMP/SAM/TE & VV12, VV23 \\
\hline & & & 0.21 & AMP/CAZ/K & VV10 \\
\hline & & & 0.21 & AMP/SAM/K & VV11 \\
\hline & & & 0.21 & AMP/CTX/K & VV21 \\
\hline & & & 0.21 & $\mathrm{AMP} / \mathrm{AK} / \mathrm{K}$ & VV25 \\
\hline & & & 0.21 & AMP/IPM/OT & VV38 \\
\hline & & & 0.21 & AMP/SAM/OT & VV41 \\
\hline & & & 0.21 & AMP/SAM/TE & VV68 \\
\hline & & & 0.21 & SAM/CTX/TE & VV69 \\
\hline & & & 0.21 & AMP/SAM/CTX & VV75 \\
\hline & & & 0.29 & AMP/SAM/CTX/OT & VV27, VV42, VV70 \\
\hline & & & 0.29 & AMP/SAM/TE/OT & VV56 \\
\hline & & & 0.29 & AMP/SAM/CTX/IPM & VV58 \\
\hline \multirow{9}{*}{1} & 1.1 & $>10$ & 0.21 & $\mathrm{AMP} / \mathrm{SAM} / \mathrm{CN}$ & VV49 \\
\hline & & & 0.29 & AMP/SAM/IPM/OT & VV45 \\
\hline & & & 0.29 & AMP/SAM/CTX/IPM & VV48 \\
\hline & & & 0.36 & AMP/SAM/CTX/IPM/TE & VV37 \\
\hline & 1.2 & 10 & 0.14 & AMP/SAM & VV67 \\
\hline & 1.2 & 10 & 0.29 & AMP/SAM/CTX/CN & VV29 \\
\hline & 1.3 & 7 & 0.14 & AMP/SAM & VV19 \\
\hline & 1.4 & 5.2 & 0.21 & AMP/SAM/IPM & VV64 \\
\hline & 1.5 & 1.5 & 0.21 & AMP/SAM/CTX & VV71 \\
\hline
\end{tabular}




\begin{tabular}{ccccll}
\hline $\begin{array}{c}\text { Number } \\
\text { of } \\
\text { plasmids }\end{array}$ & $\begin{array}{c}\text { Plasmid } \\
\text { pattern }\end{array}$ & $\begin{array}{c}\text { Plasmid } \\
\text { size }(\mathrm{kb})\end{array}$ & $\begin{array}{c}\text { MAR } \\
\text { index }\end{array}$ & \multicolumn{1}{c}{ Antibiogram } & Isolates \\
\hline & 2.1 & $>10,10$ & 0.36 & AMP/SAM/CAZ/IPM/TE & VV30 \\
& 2.2 & 10,4 & 0.14 & AMP/SAM & VV14 \\
& 2.3 & 10,2 & 0.36 & AMP/SAM/CAZ/IPM/NA & VV09 \\
2 & 2.4 & $7,6.2$ & 0.21 & AMP/SAM/CTX & VV07 \\
& 2.5 & 7,4 & 0.14 & AMP/SAM & VV24 \\
& 2.6 & $6.2,5.2$ & 0.29 & AMP/SAM/CTX/IPM & VV01 \\
\hline 3 & 3.1 & $10,6.2,2.5$ & 0.21 & AMP/SAM/CTX & VV08 \\
& 3.2 & $10,5.2,2$ & 0.29 & AMP/SAM/CTX/TE & VV35 \\
\hline 4 & 4.1 & $>10,7$, & 0.29 & AMP/SAM/CTX/IPM & VV40 \\
& & $5.2,1.5$ & & & \\
\hline
\end{tabular}

AMP (Ampicillin), SAM (Ampicillin-sulbactam), CAZ (Ceftazidime), CTX (Cefotaxime), IPM (Imipenem), AK (Amikacin), CN (Gentamicin), K (Kanamycin), TE (Tetracycline), OT (Oxytetracycline), NA (Nalidixic acid), LEV (Levofloxacin), SXT (Trimethoprim-sulfamethoxazole), C (Chloramphenicol)

\section{Discussion}

The Vibrio species are commonly found in marine environments, living in the water, sediments, plankton, aquatic animals, and flora ${ }^{[1,38,49,99]}$. Therefore, it is essential to continuously monitor the density of these pathogens to ensure the safety of seafood. The microbial load of Vibrio species in the shellfish sampled in this study is reported in Table 3. In this study, Vibrio species were recovered from all the seafood sampled from all four sampling locations. The mean total count of Vibrio species ranged from $4.66 \pm 0.40$ to 8.95 $\pm 0.00 \log \mathrm{CFU} / \mathrm{g}$. As of now, the microbiological limits of $V$. parahaemolyticus count in seafood is not regulated in Malaysia ${ }^{[88]}$. However, Letchumanan and colleagues suggested that a minimum of $5 \log$ CFU/g of Vibrio count is required to cause symptoms of Vibriosis in human hosts ${ }^{[61]}$. In the present study, 14/16 groups of shellfish samples listed in Table 3 were contaminated with more than $5 \log \mathrm{CFU} / \mathrm{g}$ of Vibrio species. Considering this, groups of shellfish that harboured a mean Vibrio count of more than $5 \mathrm{log}$ CFU/g can potentially become a health hazard to humans.

The highest mean total Vibrio count detected in this study was higher than the microbial load of Vibrio species reported by other studies conducted on seafood. In the study done by Letchumanan et al. ${ }^{[61]}$ in Malaysia, the mud crabs (Scylla serrate), flower crabs (Portunus pelagicus), carpet clams (Paphia textile) and hard shell clams (Meretrix meretrix) 
contained a microbial load of 2.45 to $6.63 \log$ CFU/g. Another study done by the same author reported the microbial load of Vibrio species ranging from $4.36 \log \mathrm{CFU} / \mathrm{mL}$ to $6.34 \mathrm{log}$ $\mathrm{CFU} / \mathrm{mL}$ in the prawns sampled from Malaysia ${ }^{[74]}$. It is also noteworthy that the findings of this study are higher than the results obtained by Lamon et al. ${ }^{[100]}$ in Italy. The mean Vibrio count in the Mediterranean mussel (Mytilus galloprovincialis) and grooved carpet shell (Ruditapes decussatus) sampled in the study were well below $5 \mathrm{log}$ CFU/g before the purification process ${ }^{[100]}$. The upward trend in the mean concentration of Vibrio species calls for the attention of the public health body to monitor the levels of this enteropathogen closely in seafood, especially in shellfish.

High levels of Vibrio species have been detected in many types of seafood samples from this region ${ }^{[61,74,88]}$. This can be attributed to the ubiquitous existence of these organisms in estuaries and coastal regions compounded by the hot climate in Malaysia, which promotes the growth of Vibrio species ${ }^{[1,38,49,88,99]}$. Nevertheless, this study has shown that the mean count of Vibrio species was significantly different among the four species of shellfish $(p<$ 0.05). The mean Vibrio count in short-necked clams was significantly higher than in both species of shrimps analysed in this study. To our best knowledge, the present study is the first to statistically analyse the difference in the microbial load of Vibrio species among different types of shellfish.

Despite the increased risk of contamination associated with all types of shellfish, the higher density of Vibrio species in short-necked clams can be linked to the filter-feeding habits of these molluscs. Bivalves such as the short-necked clams feed by filtering water through their gills, allowing bacteria and other contaminants to mobilise and concentrate in the digestive tract ${ }^{[13,32,101,102]}$. However, the findings cannot be extrapolated to all types of bivalve molluscs. This is because the microbial load of Vibrio species in the blood clams sampled in this study were not significantly higher than both species of crustaceans, disallowing a general correlation to be formed. Nonetheless, the findings of this study indicate that all shellfish are potential vehicles of transmission of the Vibrio species. The high risk of contamination directly translates into a high risk of gastroenteritis related to the consumption of crustaceans and bivalve molluscs. To avert the incidence of Vibriosis, Centers for Disease Control and Prevention (CDC) recommends boiling or steaming shellfish for an appropriate duration of time ${ }^{[78]}$. As evidenced by Liu et al. ${ }^{[103]}$, the direct exposure of shellfish to high temperatures has been shown to reduce the concentrations of the pathogen to undetectable levels ( $<3 \mathrm{MPN} / \mathrm{g}$ ), consequently ensuring safe consumption of seafood.

The toxR gene is commonly selected as the target gene in the detection of Vibrio parahaemolyticus in seafood ${ }^{[10,60,74,88,104]}$. This is because the tox $R$-PCR assay is highly 
accurate attributable to the heterogeneity in the nucleotide sequence of toxR gene among the species in the Vibrio genus ${ }^{[105,106]}$. A total of 43/77 (55.8\%) presumptive V. parahaemolyticus isolates from the shellfish samples were positive for the tox $R$ gene, confirming the presence of the pathogen. Tiger prawn was detected at the highest incidence rate $(78.9 \%)$, followed by Indian white shrimp (68.4\%), blood clam (45.0\%) and short-necked clam (31.6\%). The high prevalence of $V$. parahaemolyticus in these shellfish samples can be attributed to the temperature of seawater in tropical countries like Malaysia, which provides a conducive environment for $V$. parahaemolyticus to survive and grow in seafood ${ }^{[1,10,104,107]}$. Interestingly, the highest prevalence of $V$. parahaemolyticus was found in tiger prawns, which contained the lowest mean Vibrio count among all the shellfish samples. Conversely, the short-necked clams with the lowest incidence of the pathogen possessed the highest microbial load of Vibrio species. These findings are in line with previous studies ${ }^{[98,108]}$, which supports the use of PCR amplification over the direct plating method in identifying $V$. parahaemolyticus as the molecular detection technique has shown to produce more accurate results than the latter.

There is a considerable amount of literature concerning $V$. parahaemolyticus in seafood from Asia. Despite the subtle variation in the methodologies employed, ultimately, most studies have consistently used the toxR- or th-PCR amplification technique, which allows accurate comparisons of findings to be made ${ }^{[90,109-113]}$. The overall prevalence of $V$. parahaemolyticus in the shellfish sampled in this study is far lower compared to most studies done in other tropical and subtropical countries. In Malaysia, Narayanan et al. ${ }^{[90]}$ reported that $85.71 \%$ (120/140) of blood clam (Anadara granosa), shrimp (Penaeus species), surf clam (Paphia undulata) and squid (Loligo species) were positive for $V$. parahaemolyticus. Besides that, Narayanan et al. ${ }^{[90]}$ found that $96.8 \%$ (31/32) of the shellfish from Kerala, India, were contaminated with the pathogen. In Bangladesh, $69.44 \%$ of the shrimps harvested from farms contained $V$. parahaemolyticus, as outlined by Siddique et al. ${ }^{[110]}$. In East Asia, recent studies showed a varying incidence of the pathogen in shellfish. The occurrence of $V$. parahaemolyticus was reported as $20.0 \%$ and $14.0 \%$ in short-necked clams (Paphia variegata) and white shrimps (Penaeus vannamei) from China, which is lower than our findings ${ }^{[111]}$. In contrast, oysters (Crassostrea gigas) sampled in Kang et al. ${ }^{[113]}$ showed a higher prevalence $(85.5 \%)$ of the bacteria in their study.

In the present study, we found that the occurrence of $V$. parahaemolyticus was slightly higher in wet market samples as compared to the supermarket samples (51.2\% vs. $48.8 \%)$. To our knowledge, this is the first study to show that the prevalence of $V$. parahaemolyticus was not significantly associated with the type of establishments the shellfish are obtained from $(p>0.05)$. Unlike the present study, Tan et al. ${ }^{[88]}$ demonstrated a significantly lower 
prevalence of $V$. parahaemolyticus in short mackerels (Rastrelliger bachysoma) from hypermarkets compared to mini market and wet markets samples $(83.3 \%$ vs. $89.1 \%$ vs. 95.2\%; $p<0.05)$. In contrast, the study by Lee et al. ${ }^{[98]}$ reported a lower prevalence of the pathogen in wet market fish samples compared to fishes from the supermarket (47\% vs. $53 \%$ ). The mixed evidence on the contamination rate of shellfish in different establishments supports the idea outlined by previous studies ${ }^{[61,114]}$. These studies suggested that crosscontamination can take place at any point during handling, preparing, processing, transporting, and storing of shellfish, irrespective of the sampling site ${ }^{[61,114]}$. If the cold chain is broken, multiplication of $V$. parahaemolyticus cells can occur as a result of the exposure of shellfish to room temperature ${ }^{[115]}$. Therefore, temperature control plays a vital role in the preservation of shellfish. Liu et al. ${ }^{[103]}$ and Vasudevan et $a ._{.}^{[116]}$ have highlighted the importance of freezing in maintaining the freshness of shellfish up to the point of human consumption. Ice crystals that form during frozen storage disrupt bacterial cell structures, consequently terminating viable $V$. parahaemolyticus cells in shellfish ${ }^{[103]}$.

Historically, the two well-defined haemolysins encoded by the $t d h$ and $t r h$ genes are more frequently found in $V$. parahaemolyticus isolated from clinical samples than environmental and food samples ${ }^{[98,110,117]}$. Therefore, these putative genes provide the most discriminatory ability to detect pathogenic strains of $V$. parahaemolyticus ${ }^{[40,41]}$. Generally, the occurrence of pathogenic strains of $V$. parahaemolyticus depends on the isolation rate of the bacteria in seafood samples. As stated in the previous section, the prevalence of foodborne pathogens varies according to different geographical sites and species of seafood. Therefore, direct comparisons of the incidence of $t d h$ - and trh-positive $V$. parahaemolyticus among individual studies should be interpreted cautiously.

Although a high prevalence of $V$. parahaemolyticus was detected in the shellfish samples, none of the $V$. parahaemolyticus strains was positive for $t d h$ and $t r h$ genes. This shows that the expression of TDH and TRH does not exist among the V. parahaemolyticus strains isolated from the shellfish sampled from the wet markets and supermarkets in Selangor. The findings of our study are in agreement with several studies undertaken around this region. A study by Narayanan et al. ${ }^{[90]}$ demonstrated that all 140 samples of the bivalve molluscs and crustaceans obtained from Selangor did not present with either $t d h$ or $t r h$ genes. Similar results were also found in the study conducted by Kang et al. ${ }^{[113]}$, whereby none of the oysters (Crassostrea gigas) was contaminated with $t d h$ - or trh-positive strains of Vibrio parahaemolyticus. 
Previous studies performed in Asia have demonstrated a low occurrence of the $t d h$ and $t r h$ in the $V$. parahaemolyticus isolates from seafood. In Lee et al. ${ }^{[98]}, 4$ out of $165(2.4 \%)$ toxR-positive $V$. parahaemolyticus isolates from fish samples were positive for trh gene, whereas none of the isolates expressed the $t d h$. The oysters (Crassostrea gigas) sampled in South Korea were contaminated with $9.1 \%$ of trh-positive Vibrio parahaemolyticus. Contrastingly, none of the isolates was positive for $t d h^{[118]}$. Hu et al. ${ }^{[111]}$ demonstrated that the $2.6 \%(2 / 77)$ and $1.3 \%$ (1/77) of $V$. parahaemolyticus isolated from shellfish samples from China were positive for $t d h$ and $t r h$ gene, respectively. Despite the low prevalence of pathogenic strains of the bacteria reported in most studies, a minority of the studies conducted have illustrated a higher incidence of pathogenic V. parahaemolyticus strains in seafood. For instance, $21.95 \%$ of shrimp and $18.75 \%$ of fish samples from China were contaminated with trh-positive Vibrio parahaemolyticus, whereas the prevalence of $t d h$ was $7.32 \%$ and $15.63 \%$ in shrimps and fish, respectively ${ }^{[119]}$. As outlined by Raghunath ${ }^{[41]}$, the vast difference in the occurrence of $t d h$ - and $t r h$-positive strains demonstrated by individual studies is attributable to the different sampling sites, source of shellfish and detection method of the bacteria.

There is still insufficient data to conclude that all the V. parahaemolyticus strains in this present study are non-pathogenic, based entirely on the absence of $t d h$ and $t r h$ genes. This is because several other mechanisms are involved in the mediation of virulence in this pathogen, such as the $t l h$, T3SS, T6SS, biofilm, siderophore and protease production ${ }^{[15,120-}$ ${ }^{123]}$. Besides that, the demonstration of $\beta$-haemolytic action, which is highly specific to $t d h$, was recently seen in $t d h$ and trh-negative strains of Vibrio parahaemolyticus ${ }^{[90,124]}$. This raises questions on the involvement of mechanisms apart from the $t d h$, the Kanagawa phenomenon (KP) action of the bacteria ${ }^{[43,125,126]}$. Despite the absence of $t d h$-and $t r h$-positive $V$. parahaemolyticus strains in the present study, continuous monitoring of the shellfish sold in this region is important to ensure the food safety of seafood products. However, it is imperative that future work targets other virulence factors to determine the pathogenicity of the $V$. parahaemolyticus strains in seafood.

The antibiotic susceptibility test was performed for all $43 \mathrm{~V}$. parahaemolyticus isolates from the shellfish samples. The results show that nearly all of the bacterial isolates $(95.3 \%)$ were resistant to ampicillin. However, resistance to $\beta$-lactams such as ampicillin is not uncommon in $V$. parahaemolyticus. Due to the misuse and overuse of ampicillin in aquaculture, high incidences of ampicillin-resistant $V$. parahaemolyticus have been reported extensively in literature worldwide ${ }^{[55,61,90,98,118,119]}$. The increasing trend in the minimum inhibition concentration (MIC) of ampicillin from $64 \mu \mathrm{g} / \mathrm{mL}$ in 2011 to $128 \mu \mathrm{g} / \mathrm{mL}$ in 2013, as outlined by Al-Othrubi et al. ${ }^{[60]}$, have highlighted the worsening case of resistance against 
this drug. Although ampicillin is not used in the management of Vibriosis, these findings are of great concern as it impedes the role of ampicillin in the empirical management of bacterial infections $^{[55]}$. Besides that, most of the $V$. parahaemolyticus isolates were also resistant to ampicillin-sulbactam (81.4\%). Alarmingly, this value is much higher than those reported by other studies in Malaysia ${ }^{[74,88,90]}$. Although the sample source and detection methods could have contributed to the differences, the resistance to $\beta$-lactam/ $\beta$-lactamase inhibitor drug in this study should still be highlighted, considering the significance of the drug in treating infections caused by $\beta$-lactamase-containing S. aureus, H. influenzae and E. coli ${ }^{[81,127]}$.

A notable resistance pattern was observed with cefotaxime (37.2\%) in the present study. On the contrary, most of the V. parahaemolyticus isolates were found to be sensitive to ceftazidime (55.8\%). Similar resistance patterns to third-generation cephalosporins were also demonstrated by other studies, including the study done by Narayanan et al. ${ }^{[90]}$. In Lee et al. ${ }^{[98]}$, more than half $(52 \%)$ of the $V$. parahaemolyticus isolates were resistant to cefotaxime, whereas $48 \%$ of these isolates exhibited resistance to ceftazidime. Meanwhile, Kang et al. ${ }^{[118]}$ reported that most isolates (63.6\%) from oysters (Crassostrea gigas) were sensitive to cefotaxime. This study also demonstrated that none of the $V$. parahaemolyticus strains was resistant to the aforementioned drug. The discrepancies in the literature regarding the resistance of $V$. parahaemolyticus to third-generation cephalosporins reflects on the antibiotic-prescribing practices in the local setting. However, the resistance to $\beta$-lactams like this group of antibiotics is a significant public health threat. The recent discoveries of extended-spectrum beta-lactamases (ESBL) - producing strains of $V$. parahaemolyticus in Korea and India raise concerns about the spread of these strains locally ${ }^{[128,129]}$.

Carbapenems such as imipenem are proven effective in providing complete coverage in human infections resulting from ESBL-producing organisms ${ }^{[130,131]}$. Carbapenems are also frequently used as the drug of last resort in infections caused by Gram-positive and Gramnegative bacteria ${ }^{[82,83]}$. The over-reliance on carbapenems have therefore resulted in the increasing resistance to these group of drugs. This is evidenced by the $23.3 \%$ resistance rate to imipenem in the present study. These results tie well with similar studies done in this region. Lee et al. ${ }^{[98]}$ have reported that $12.0 \%$ of the $V$. parahaemolyticus isolated from marine fish and freshwater fish were resistant to imipenem. Similarly, a low incidence (2\%) of imipenem resistance was detected in $V$. parahaemolyticus isolated from banana prawns and red prawns from Malaysia ${ }^{[74]}$. Letchumanan et al. ${ }^{[61]}$ showed that $0.5 \%$ out of 200 isolates from crustaceans and bivalve molluscs were resistant to the same drug. Contrary to these findings, Narayanan et al. ${ }^{[90]}$ and Siddique et al. ${ }^{[110]}$ found that all the V. parahaemolyticus isolates from the seafood samples were susceptible to carbapenems such as imipenem and 
meropenem. The low resistance rates show that the global resistance to this group of antibiotics is still at the initial stage. Hence, immediate action is needed to preclude the further spread of carbapenem resistance among $V$. parahaemolyticus in seafood.

In the present study, high susceptibility rates to quinolones (levofloxacin, 97.7\%; nalidixic acid, 95.3\%) were seen. These findings are in line with other literature that has reported similar susceptibility patterns to quinolones ${ }^{[90,119]}$. The consistently high sensitivity of $V$. parahaemolyticus to quinolones reinforces the usage of these antimicrobials in the management of Vibriosis, thus reducing mortality rates caused by the disease ${ }^{[77,78]}$. The isolates in this study were highly susceptible to trimethoprim-sulfamethoxazole (100\%), chloramphenicol (100\%), aminoglycosides (gentamicin, 93\%; amikacin, 90.7\%; kanamycin, 69.8\%) and tetracyclines (oxytetracycline, 81.4\%; tetracycline, 74.4\%). Similarly, a study reported high susceptibility of $V$. parahaemolyticus isolates to chloramphenicol $(91.04 \%)$, tetracycline $(83.58 \%)$, and aminoglycosides such as gentamicin $(74.63 \%)$ and amikacin $(65.67 \%)^{[88]}$. Several other studies have also found high sensitivity rates to these groups of antibiotics in $V$. parahaemolyticus from food sources ${ }^{[90,132]}$.

In this study, the MAR index of the $V$. parahaemolyticus isolates ranges from 0.00 to 0.36 . Three isolates exhibited resistance to five antibiotics, yielding the highest MAR index value seen in this study. Although the MAR index provides a good measure of the severity of antibiotic resistance in the samples, comparisons of MAR indices between studies are impossible to make due to the variation in the types of antibiotics tested and the total number of antibiotics used in individual studies. For example, Narayanan et al. ${ }^{[90]}$ demonstrated that the MAR indices of $V$. parahaemolyticus isolates ranged from 0.00 to 0.71 . The isolate with the highest MAR index was resistant to 17 out of 24 antibiotics. However, in Siddique et $a l .{ }^{[110]}$, the MAR index ranged from 0.07 to 0.27 , and the highest MAR index was demonstrated by $V$. parahaemolyticus isolates that were resistant to four out of 15 antibiotics.

Bacterial isolates with a MAR index of more than 0.2 reflects the origin of the strain from contaminated sources such as aquaculture and agriculture farms ${ }^{[97,98]}$. The excessive usage of antibiotics in these sectors exerts selection pressure on the microflora in the water and soil, resulting in the growth of multi-drug resistant organisms ${ }^{[53,59,133]}$. Alternatively, isolates that have MAR indices less than 0.2, are thought to have originated from a low-risk source with lesser exposure to antibiotics ${ }^{[98]}$. In this study, $69.8 \%$ of the V. parahaemolyticus isolates had MAR indices of more than 0.2. A chi-squared test showed that the number of bacterial isolates with a MAR index of more than 0.2 , was not significantly different between wet market and supermarket samples $(p=0.054)$. This suggests that the shellfish from wet 
markets and supermarkets had similar levels of exposure to antibiotics. Seafood samples from both locations are at equally high risk of transmitting multidrug resistant strains.

The advent and widespread usage of antibiotics for over 80 years have exerted selection pressure on bacteria such as $V$. parahaemolyticus. This has resulted in resistance against these therapeutic agents, as demonstrated in the present study. Antibiotics like ampicillin are excessively used in the agriculture industry and healthcare sectors ${ }^{[52]}$. Antimicrobials are used to prevent, treat and control diseases and promote the growth of marine products in the aquaculture industry ${ }^{[52,53]}$. In the healthcare setting, antibiotics are often used to treat self-limiting infections and indefinite diagnoses ${ }^{[52,134]}$. Ultimately, these anthropogenic activities involving the widespread usage of antibiotics have resulted in $V$. parahaemolyticus developing multi-drug resistance against common antibiotics ${ }^{[55]}$. The development of multi-drug resistance in $V$. parahaemolyticus is a public health and therapeutic concern. This is because these resistance genes can spread to human hosts through the consumption of contaminated seafood. Resistance genes can also be transmitted to human hosts via the lateral gene transfer of mobile genetic elements with resistance genes, from $V$. parahaemolyticus to other human pathogens ${ }^{[1,59]}$.

Plasmids are one of the mobile genetic elements that contain important genes for bacterial survival, such as genetic elements encoding antibiotic resistance ${ }^{[135,136]}$. The selection pressure exerted by the frequent exposure to antibiotics promotes the transmission of plasmids with resistance genes among bacterial cells ${ }^{[53,59,133]}$. Therefore, profiling plasmids in bacteria like $V$. parahaemolyticus provides a better understanding of the mediation of antibiotic resistance in these bacteria. In this study, 18 out of 43 (41.9\%) $\mathrm{V}$. parahaemolyticus isolates possess one to four plasmid DNA bands, ranging from $1 \mathrm{~kb}$ to more than $10 \mathrm{~kb}$ in size. These findings are in line with other studies that have detected plasmid DNA in $V$. parahaemolyticus isolated from seafood ${ }^{[61,98,137]}$.

However, the majority of the bacterial isolates in the present study did not harbour any plasmid. Based on the plasmid profiles of the isolates mentioned, 25/43 V. parahaemolyticus isolates $(58.1 \%$ ) were devoid of any plasmids. Interestingly, all except one of the bacterial strains (VV34) without plasmid were resistant to at least one antibiotic tested in this study. It can be postulated that the antibiotic resistance in these $V$. parahaemolyticus isolates was intrinsically mediated via chromosomes. Since $V$. parahaemolyticus exists ubiquitously in aquatic environments, they are constantly exposed to residues of antibiotics used in aquaculture, farming, and healthcare sectors. Antibiotics used in these economic sectors are often released into wastewater treatment plants ${ }^{[138]}$. The residual antibiotics in wastewater, compounded by antibiotics used in aquaculture, promote the growth of resistant 
$V$. parahaemolyticus via the mutation of genes that control the activity of antibiotics in the cell $^{[53,59,133,139]}$. Once a resistant mutant emerges, the antibiotic terminates strains sensitive to the antibiotic. Ultimately, this allows the resistant $V$. parahaemolyticus to thrive in the marine environment ${ }^{[139]}$. The findings of our study are in strong agreement with previous studies which have reported chromosomal mediation of antibiotic resistance in their respective studies $^{[61,98,140]}$.

The plasmid profiles of the $V$. parahaemolyticus isolates from the shellfish samples showed that the isolates that were resistant to the highest number of antibiotics tested $(5 / 14)$ had relatively larger plasmids. Therefore, we cannot rule out the possibility of a relationship between plasmid sizes and the number of antibiotic resistance genes possessed by a bacterium. It is worth noting that in most cases, larger plasmids in Gram-negative bacteria are conjugative plasmids. These plasmid DNA bands possess a higher number of DNA base pairs which codes for the conjugation function of the bacteria ${ }^{[141]}$. Another striking pattern encountered in this study is the possession of at least one plasmid in most of Vibrio parahaemolyticus isolates $(9 / 10 ; 90 \%)$ that were resistant to imipenem. This suggests the possibility of the imipenem resistance being acquired through laterally transferable plasmids that encode for carbapenemase genes ${ }^{[142,143]}$. However, existing studies have only described the chromosomal mediation of carbapenem resistance in $V$. parahaemolyticus $^{[98,144]}$. Therefore, further analysis through plasmid curing assay is required to determine the role of plasmids in the antibiotic resistance phenotype of the $V$. parahaemolyticus isolates in this study ${ }^{[145]}$.

There are several potential non-antibiotic methods that been effective against $V$. parahaemolyticus and dealing with antibiotic-resistant strains. Recently, bacteriophages or phage therapy has regained renewed interest in controlling Vibriosis and multidrug-resistant bacteria $^{[80,146,147]}$. These phages are host specific, induces bacteriolysis and immediate counter action, readily isolated, cost effective, and generate less adverse effect compared to antibiotics $^{[148-150]}$. The use of phage therapy in the aquaculture sector will eventually reduce the dependency for antibiotics and will allow the bacteria strains to lose their resistance traits $^{[151-153]}$.

Besides, recent literatures have been evidence in bioprospecting for natural products derived from plants ${ }^{[154,155]}$, microbial origins ${ }^{[156-158]}$ or animals with potential antimicrobial properties to fight against multidrug Vibrio strains ${ }^{[159-161]}$. Streptomyces sp., a soil derived bacteria has exhibited valuable properties to be biocontrol agent of Vibrio $^{[150,162-165]}$ and as probiotic in aquculture or animal husbandry ${ }^{[166-170]}$. These natural bacteria are safer and does not couse any resistance traits similar to antibiotics. Hence, the application of phage therapy 
and Streptomyces sp. probiotics should be introduced in aquaculture sectors as a tool agaisnt bacterial infections and reduce the dependency towards antibiotics.

\section{Conclusion}

In summary, high densities of Vibrio species ( $>5 \log$ CFU/g) were found in 14 out of 16 groups of shellfish, increasing the risk of foodborne infection in human hosts. While most of the seafood analysed (55.8\%) were contaminated with $V$. parahaemolyticus, none of the isolates harboured the genes encoding for TDH and TRH. This shows that all the strains of the bacteria are non-pathogenic. However, the complexity in the virulence mechanism of this bacteria calls for future studies to explore other factors facilitating the pathogenicity of $V$. parahaemolyticus. Besides that, the bacterial isolates exhibited resistance to different antibiotics. High resistance rates were seen towards common antibiotics such as ampicillin, ampicillin-sulbactam, cefotaxime and imipenem. The seriousness of antibiotic resistance is also reflected in the high proportion $(69.8 \%)$ of $V$. parahaemolyticus isolates exhibiting a MAR index of more than 0.2. This is a threat to public health because the transmission of antibiotic resistance genes can occur via the lateral transfer of plasmids among bacterial cells. Since $41.9 \%$ of the $V$. parahaemolyticus isolates were shown to have plasmid DNAs, it is imperative to take immediate action to curb multi-drug resistance in $V$. parahaemolyticus. The relevant agencies should closely monitor and control the use of antibiotics in aquaculture, aqriculture and animal husbandry.

Author Contributions: VV performed the research work, data analysis and manuscript writing. LT-HT, JWFL, H-LS, VL, and PP provided conceptualisation, technical support, and proofreading. PP set up this research project. All authors have read and agreed to the published version of the manuscript.

Funding: This Bachelor of Medical Science research project was funded by Jeffrey Cheah School of Medicine and Health Sciences.

Acknowledgments: Authors would like to thank Professor Dr. Shajahan Yasin, Professor, and Head of School, Jeffrey Cheah School of Medicine and Health Sciences, Monash University Malaysia for his endless support.

Conflicts of Interest: The authors declare no conflict of interest.

\section{References}

1. Elbashir S, Parveen S, Schwarz J, et al. Seafood pathogens and information on antimicrobial resistance: A review. Food Microbiol 2018; 70: 85-93.

2. Mozaffarian D and Wu JHY, Omega-3 fatty acids and cardiovascular disease: effects on risk factors, molecular pathways, and clinical events. J Am Coll Cardiol 2011; 58(20): 2047-2067.

3. Rondanelli M, Rigon C, Perna S, et al., Novel insights on intake of fish and prevention of sarcopenia: all reasons for an adequate consumption. Nutrients 2020; 12(2): 307.

4. Aucoin M, Cooley K, Knee C, et al., Fish-derived omega-3 fatty acids and prostate cancer: A systematic review. Integr Cancer Ther 2017; 16(1): 32-62.

5. Middleton P, Gomersall JC, Gould JF, et al., Omega-3 fatty acid addition during pregnancy. Cochrane Database Syst Rev 2018(11). 
6. Hartweg J, Perera R, Montori VM, et al., Omega-3 polyunsaturated fatty acids (PUFA) for type 2 diabetes mellitus. Cochrane Database Syst Rev 2008; 2008(1): CD003205.

7. Food and Agriculture Organization of the United Nations. The state of world fisheries and aquaculture 2020. 2020. Available at: http://www.fao.org/state-of-fisheries-aquaculture [Accessed on 21 August 2021].

8. OECD, Food, and Nations AOotU, OECD-FAO Agricultural Outlook 2017-2026. 2017.

9. Hishamunda N, Bueno P, Ridler N, et al., Analysis of aquaculture development in Southeast Asia. 2009: Food and Agriculture Organization of the United Nations (FAO).

10. Nakaguchi Y, Contamination with Vibrio parahaemolyticus and its virulent strains in seafood marketed in Thailand, Vietnam, Malaysia, and Indonesia from 2008 to 2011. Trop Med Health 2013; advpub.

11. Chintagari S, Hazard N, Edwards G, et al., Risks Associated with Fish and Seafood. Microbiol Spectr 2017; 5(1).

12. Lee R, Rangdale R, Croci L, et al., Bacterial pathogens in seafood. 2008.

13. Razafimahefa RM, Ludwig-Begall LF, and Thiry E, Cockles and mussels, alive, alive, oh-The role of bivalve molluscs as transmission vehicles for human norovirus infections. Transbound Emerg Dis 2020; 67(S2): 9-25.

14. Venugopal V and Gopakumar K, Shellfish: nutritive value, health benefits, and consumer safety. Compr Rev Food Sci Food Saf 2017; 16(6): 1219-1242.

15. Letchumanan V, Chan K-G, and Lee L-H, Vibrio parahaemolyticus: A review on the pathogenesis, prevalence, and advance molecular identification techniques. Front Microbiol 2014; 5(705).

16. Heng S-P, Letchumanan V, Deng C-Y, et al., Vibrio vulnificus: An environmental and clinical burden. Front Microbiol 2017; 8: 997.

17. Letchumanan V, Ser H-L, Tan W-S, et al., Genome sequence of Vibrio parahaemolyticus VP152 strain isolated from Penaeus indicus in Malaysia. Front Microbiol 2016; 7: 1410.

18. Law JWF, Letchumanan V, Chan KG, et al., Insights into detection and identification of foodborne pathogens. Food Borne Pathogens and Antibiotic Resistance. 2016: John Wiley \& Sons, Inc.

19. Letchumanan V, Ab Mutalib N-S, Wong SH, et al., Determination of antibiotic resistance patterns of Vibrio parahaemolyticus from shrimp and shellfish in Selangor, Malaysia. Prog Microbes Mol Biol 2019; 2(1): a0000019.

20. Khoo C-H, Cheah Y-K, Lee L-H, et al., Virulotyping of Salmonella enterica subsp. enterica isolated from indigenous vegetables and poultry meat in Malaysia using multiplex-PCR. Antonie Van Leeuwenhoek 2009; 96(4): 441-457.

21. Yoke-Kqueen C, Learn-Han L, Noorzaleha A, et al., Characterization of multiple-antimicrobialresistant Salmonella enterica subsp. enterica isolated from indigenous vegetables and poultry in Malaysia. Lett Appl Microbiol 2008; 46(3): 318-324.

22. Cheah Y-K, Salleh NA, Lee L-H, et al., Comparison of PCR fingerprinting techniques for the discrimination of Salmonella enterica subsp. enterica serovar Weltevreden isolated from indigenous vegetables in Malaysia. World J Microb Biot 2008; 24(3): 327-335.

23. Learn-Han L, Yoke-Kqueen C, Salleh NA, et al., Analysis of Salmonella agona and Salmonella weltevreden in Malaysia by PCR fingerprinting and antibiotic resistance profiling. Antonie Van Leeuwenhoek 2008; 94(3): 377-387. 
24. Learn-Han L, Yoke-Kqueen C, Shiran M, et al., Molecular characterization and antimicrobial resistance profiling of Salmonella enterica subsp. enterica isolated from 'Selom'(Oenanthe stolonifera). Int Food Res J 2009; 16(1): 191-202.

25. Eng S-K, Pusparajah P, Ab Mutalib N-S, et al., Salmonella: A review on pathogenesis, epidemiology and antibiotic resistance. Front Life Sci 2015; 8(3): 284-293.

26. Letchumanan V, Loo K-Y, Law JW-F, et al., Vibrio parahaemolyticus: The protagonist of foodborne diseases. Prog Microbes Mol Biol 2019; 2(1): a0000029.

27. Law JW-F, Ab Mutalib N-S, Chan K-G, et al., An insight into the isolation, enumeration, and molecular detection of Listeria monocytogenes in food. Front Microbiol 2015; 6: 1227.

28. Law JW-F, Ab Mutalib N-S, Chan K-G, et al., Rapid methods for the detection of foodborne bacterial pathogens: principles, applications, advantages and limitations. Front Microbiol 2015; 5: 770.

29. Letchumanan V, Wong P-C, Goh B-H, et al., A review on the characteristics, taxanomy and prevalence of Listeria monocytogenes. Prog Microbes Mol Biol 2018; 1(1): a0000007.

30. Loo K-Y, Letchumanan V, Dhanoa A, et al., Exploring the pathogenesis, clinical characteristics and therapeutic regimens of Listeria monocytogenes. Acta Sci Microbiol 2020; 3: 01-13.

31. Israel $\mathrm{P}$, Alona $\mathrm{P}$, and Majed $\mathrm{O}$, Infectious outbreaks associated with bivalve shellfish consumption: A worldwide perspective. Clin Infect Dis 2002; 35(8): 921-928.

32. World Health Organization and Food and Agriculture Organization of the United Nations. Risk assessment of Vibrio parahaemolyticus in seafood. Microbiological Risk Assessment Series 2011. [Accessed on 21 August 2021].

33. Yan W, Ji L, Xu D, et al., Molecular characterization of clinical and environmental Vibrio parahaemolyticus isolates in Huzhou, China. PLoS One 2020; 15(10): e0240143.

34. Nair GB, Ramamurthy T, Bhattacharya SK, et al., Global dissemination of Vibrio parahaemolyticus serotype O3:K6 and its serovariants. Clin Microbiol Rev 2007; 20(1): 39-48.

35. Anupama KP, Deeksha K, Deeksha A, et al., Comparative performance of TCBS and TSA for the enumeration of trh+ Vibrio parahaemolyticus by direct colony hybridization. J Microbiol Methods 2019; 157: 37-42.

36. Lee L-H and Raghunath P, Vibrionaceae diversity, multidrug resistance and management. Front Microbiol 2018; 9: 563.

37. Saha D and LaRocque RC, 43 - Cholera and other Vibrios, in Hunter's Tropical Medicine and Emerging Infectious Disease (Ninth Edition), A.J. Magill, et al., Editors. 2013, W.B. Saunders: London. p. 448-453.

38. Baker-Austin C, Oliver JD, Alam M, et al., Vibrio spp. infections. Nat Rev Dis Primers 2018; 4: 119.

39. Yang H, de Souza Santos M, Lee J, et al., A novel mouse model of enteric Vibrio parahaemolyticus infection reveals that the type III secretion system 2 effector VopC plays a key role in tissue invasion and gastroenteritis. mBio 2019; 10(6): e02608-19.

40. Chao G, Jiao X, Zhou X, et al., Systematic functional pandemic strain--specific genes, three genomic islands, two T3SSs in foodborne, and clinical Vibrio parahaemolyticus isolates in China. Foodborne Pathog Dis 2009; 6: 689+.

41. Raghunath P, Roles of thermostable direct hemolysin (TDH) and TDH-related hemolysin (TRH) in Vibrio parahaemolyticus. Front Microbiol 2015; 5(805). 
42. Shimohata $\mathrm{T}$ and Takahashi A, Diarrhea induced by infection of Vibrio parahaemolyticus. J Med Invest 2010; 57(3,4): 179-82.

43. Bej AK, Patterson DP, Brasher CW, et al., Detection of total and hemolysin-producing Vibrio parahaemolyticus in shellfish using multiplex PCR amplification of tl, tdh and trh. J Microbiol Methods 1999; 36(3): 215-225.

44. Takahashi A, Kenjyo N, Imura K, et al., $\mathrm{Cl}^{-}$secretion in colonic epithelial cells induced by the vibrio parahaemolyticus hemolytic toxin related to thermostable direct hemolysin. Infect Immun 2000; 68(9): 5435-5438.

45. Cai Y and Ni Y, Purification, characterization, and pathogenicity of urease produced by Vibrio parahaemolyticus. J Clin Lab Anal 1996; 10(2): 70-73.

46. Honda T, Ni YX, and Miwatani T, Purification and characterization of a hemolysin produced by a clinical isolate of Kanagawa phenomenon-negative Vibrio parahaemolyticus and related to the thermostable direct hemolysin. Infect Immun 1988; 56(4): 961-965.

47. Park KS, Ono T, Rokuda M, et al., Cytotoxicity and enterotoxicity of the thermostable direct hemolysin-deletion mutants of Vibrio parahaemolyticus. Microbiol Immunol 2004; 48(4): 313-318.

48. Xu M, Yamamoto K, and Honda T, Construction and characterization of an isogenic mutant of Vibrio parahaemolyticus having a deletion in the thermostable direct hemolysin-related hemolysin gene (trh). J Bacteriol 1994; 176(15): 4757-4760.

49. O'Boyle N and Boyd A, Manipulation of intestinal epithelial cell function by the cell contact-dependent type III secretion systems of Vibrio parahaemolyticus. Front Cell Infect Microbiol 2014; 3: 114.

50. Ottaviani D, Leoni F, Serra R, et al., Nontoxigenic Vibrio parahaemolyticus strains causing acute gastroenteritis. J Clin Microbiol 2012; 50(12): 4141-4143.

51. Letchumanan V, Chan K-G, Khan TM, et al., Bile sensing: The activation of Vibrio parahaemolyticus virulence. Front Microbiol 2017; 8: 728.

52. Laxminarayan R, Duse A, Wattal C, et al., Antibiotic resistance-the need for global solutions. Lancet Infect Dis 2013; 13(12): 1057-1098.

53. Marshall BM and Levy SB, Food animals and antimicrobials: Impacts on human health. Clin Microbiol Rev 2011; 24(4): 718-733.

54. Low CX, Tan LT-H, Ab Mutalib N-S, et al., Unveiling the impact of antibiotics and alternative methods for animal husbandry: A review. Antibiotics 2021; 10(5): 578.

55. Loo K-Y, Letchumanan V, Law JW-F, et al., Incidence of antibiotic resistance in Vibrio spp. Rev Aquacult 2020; 12(4): 2590-2608.

56. Letchumanan V, Ser H-L, Chan K-G, et al., Genome sequence of Vibrio parahaemolyticus VP103 strain isolated from shrimp in Malaysia. Front Microbiol 2016; 7: 1496.

57. Letchumanan V, Tan W-S, Yin W-F, et al., Genome sequence of Vibrio sp. OULL4 isolated from shellfish. Prog Microbes Mol Biol 2020; 3(1): a0000066.

58. Davison HC, Woolhouse MEJ, and Low JC, What is antibiotic resistance and how can we measure it? Trends Microbiol 2000; 8(12): 554-559.

59. World Health Organization, Food and Agriculture Organization of the United Nations, and World Organisation for Animal Health. Report of a joint FAO/OIE/WHO expert consultation on antimicrobial use in aquaculture and antimicrobial resistance. 2006. [Accessed on 21 August 2021]. 
60. Al-Othrubi S, Kqueen C, Mirhosseini H, et al., Antibiotic resistance of Vibrio parahaemolyticus isolated from cockles and shrimp sea food marketed in Selangor, Malaysia. Clin Microbiol 2014; 3 : 148.

61. Letchumanan V, Pusparajah P, Tan LT, et al., Occurrence and antibiotic resistance of Vibrio parahaemolyticus from shellfish in Selangor, Malaysia. Front Microbiol 2015; 6: 1417.

62. Sahilah AM, Laila RAS, Sallehuddin HM, et al., Antibiotic resistance and molecular typing among cockle (Anadara granosa) strains of Vibrio parahaemolyticus by polymerase chain reaction (PCR)based analysis. World J Microb Biot 2014; 30(2): 649-659.

63. Kaysner CA, Angelo DePaola J, and Jones J. BAM Chapter 9: Vibrio. 2019. Available at: https://www.fda.gov/food/laboratory-methods-food/bam-chapter-9-vibrio [Accessed on 21 August 2021].

64. World Health Organization and Food and Agriculture Organization of the United Nations. Risk assessment tools for Vibrio parahaemolyticus and Vibrio vulnificus associated with seafood.

Microbiological risk assessment 2020 Available at:

https://apps.who.int/iris/bitstream/handle/10665/330867/9789240000186-

eng.pdf? sequence $=1 \&$ is Allowed=y [Accessed on 21 August 2021].

65. Da Silva N, Taniwaki MH, Junqueira VC, et al., Microbiological examination methods of food and water: a laboratory manual. 2018: CRC Press.

66. Gomez-Gil B and Roque A, Isolation, enumeration, and preservation of the Vibrionaceae. 2006, Washington, DC, USA: ASM Press: Washington, DC, USA. p. 15-26.

67. Silvester R, Alexander D, and Ammanamveetil MHA, Prevalence, antibiotic resistance, virulence and plasmid profiles of Vibrio parahaemolyticus from a tropical estuary and adjoining traditional prawn farm along the southwest coast of India. Ann Microbiol 2015; 65(4): 2141-2149.

68. da Silva N, Taniwaki MH, Junqueira VCA, et al., Basic plate count techniques for enumeration of microorganisms. 2019, CRC Press. p. 25-46.

69. HiMedia ${ }^{\mathrm{TM}}$. HiCrome $^{\mathrm{TM}}$ Vibrio Agar M1682. 2020. Available at: https://himedialabs.com/TD/M1682.pdf [Accessed on 21 August 2021].

70. Hara-Kudo Y, Nishina T, Nakagawa H, et al., Improved method for detection of Vibrio parahaemolyticus in seafood. Appl Environ Microbiol 2001; 67(12): 5819-5823.

71. Bisha B, Simonson J, Janes M, et al., A review of the current status of cultural and rapid detection of Vibrio parahaemolyticus. Int J Food Sci Technol 2012; 47(5): 885-899.

72. Barbosa C, Nogueira S, Gadanho M, et al., DNA extraction: Finding the most suitable method. 2015. p. 135-154.

73. Yung Bu K, Jun O, Chiho M, et al., Identification of Vibrio parahaemolyticus strains at the species level by PCR targeted to the toxR gene. J Clin Microbiol 1999; 37(4): 1173-1177.

74. Letchumanan V, Yin W-F, Lee L-H, et al., Prevalence and antimicrobial susceptibility of Vibrio parahaemolyticus isolated from retail shrimps in Malaysia. Front Microbiol 2015; 6(33).

75. Kim YB, Okuda J, Matsumoto C, et al., Identification of Vibrio parahaemolyticus strains at the species level by PCR targeted to the toxR gene. J Clin Microbiol 1999; 37(4): 1173-1177.

76. Terzi G, Büyüktanır Ö, and Yurdusev N, Detection of the tdh and trh genes in Vibrio parahaemolyticus isolates in fish and mussels from Middle Black Sea Coast of Turkey. Lett Appl Microbiol 2009; 49(6): 757-763. 
77. Wong KC, Brown AM, Luscombe GM, et al., Antibiotic use for Vibrio infections: IMPORTANT insights from surveillance data. BMC Infect Dis 2015; 15: 226-226.

78. Centers for Disease Control and Prevention. Vibrio species causing Vibriosis. 2019. Available at: https://www.cdc.gov/vibrio/investigations/rawoysters-05-19/index.html [Accessed on 21 August 2021].

79. Centers for Disease Control and Prevention. Cholera - Vibrio cholerae infection. 2020. Available at: https://www.cdc.gov/cholera/treatment/antibiotic-treatment.html\#summary [Accessed on 21 August 2021].

80. Letchumanan V, Chan K-G, Pusparajah P, et al., Insights into bacteriophage application in controlling Vibrio species. Front Microbiol 2016; 7: 1114.

81. Peechakara BV and Gupta M, Ampicillin/Sulbactam. StatPearls [Internet]. 2020, Treasure Island, Florida: StatPearls Publishing.

82. Fernandes R, Amador P, and Prudêncio C, $\beta$-Lactams: chemical structure, mode of action and mechanisms of resistance. Rev Med Microbiol 2013; 24(1): 7-17.

83. Hawkey PM and Livermore DM, Carbapenem antibiotics for serious infections. BMJ 2012; 344.

84. Vardanyan RS and Hruby VJ, 34 - Antimycobacterial Drugs, in Synthesis of Essential Drugs, R.S. Vardanyan and V.J. Hruby, Editors. 2006, Elsevier: Amsterdam. p. 525-534.

85. Garneau-Tsodikova S and Labby KJ, Mechanisms of resistance to aminoglycoside antibiotics: Overview and perspectives. MedChemComm 2016; 7(1): 11-27.

86. Kemnic TR and Coleman M, Trimethoprim Sulfamethoxazole. StatPearls [Internet]. 2018, Treasure Island, Florida: StatPearls Publishing.

87. Lorenzo D, Chloramphenicol resurrected: A journey from antibiotic resistance in eye infections to biofilm and ocular microbiota. Microorganisms 2019; 7(9): 278.

88. Tan CW, Malcolm TTH, Kuan CH, et al., Prevalence and antimicrobial susceptibility of Vibrio parahaemolyticus isolated from short mackerels (Rastrelliger brachysoma) in Malaysia. Front Microbiol 2017; 8(1087).

89. Irving W, Boswell T, and Ala'Aldeen D, BIOS Instant Notes in Medical Microbiology. 2005, CT, UNITED STATES: Taylor \& Francis Group.

90. Narayanan SV, Joseph TC, Peeralil S, et al., Prevalence, virulence characterization, AMR pattern and genetic relatedness of Vibrio parahaemolyticus isolates from retail seafood of Kerala, India. Front Microbiol 2020; 11(592).

91. Saifedden G, Farinazleen G, Nor-Khaizura A, et al., Antibiotic Susceptibility profile of Vibrio parahaemolyticus isolated from shrimp in Selangor, Malaysia. Int Food Res J 2016; 23(6): 2732-2736.

92. Institute CaLS, Methods for antimicrobial dilution and disk susceptibility testing of infrequently isolated or fastidious bacteria. 3rd ed. ed. Methods for antimicrobial dilution and disk susceptibility testing of infrequently Isolated or fastidious bacteria. 2016, Wayne, PA: Wayne, PA Clinical and Laboratory Standards Institute.

93. Krumperman PH, Multiple antibiotic resistance indexing of Escherichia coli to identify high-risk sources of fecal contamination of foods. Appl Environ Microbiol 1983; 46(1): 165-170.

94. Aldred KJ, Kerns RJ, and Osheroff N, Mechanism of quinolone action and resistance. Biochemist 2014; 53(10): 1565-1574. 
95. Reis W, Gaio J, Trang T, et al., Antibiotics, in Pharmacology in Clinical Neurosciences: A Quick Guide, H. Prabhakar, C. Mahajan, and I. Kapoor, Editors. 2020, Springer Singapore: Singapore. p. 265-497.

96. Irving WL, Medical microbiology, ed. D.A.A. Ala'Aldeen and T. Boswell. 2005: Abingdon : Taylor \& Francis.

97. M Kurdi Al-Dulaimi M, Abd Mutalib S, Abd Ghani M, et al., Multiple antibiotic resistance (MAR), plasmid profiles, and DNA polymorphisms among Vibrio vulnificus isolates. Antibiotics 2019; 8(2): 68.

98. Lee L-H, Ab Mutalib N-S, Law JW-F, et al., Discovery on antibiotic resistance patterns of Vibrio parahaemolyticus in Selangor reveals carbapenemase producing Vibrio parahaemolyticus in marine and freshwater fish. Front Microbiol 2018; 9: 2513-2513.

99. You KG, Bong CW, and Lee CW, Antibiotic resistance and plasmid profiling of Vibrio spp. in tropical waters of Peninsular Malaysia. Environ Monit Assess 2016; 188(3): 171.

100. Lamon S, Consolati SG, Fois F, et al., Occurrence, seasonal distribution, and molecular characterization of Vibrio vulnificus, Vibrio cholerae, and Vibrio parahaemolyticus in shellfish (Mytilus galloprovincialis and Ruditapes decussatus) collected in Sardinia (Italy). J Food Prot 2019; 82(11): 1851-1856.

101. Tantillo GM, Fontanarosa M, Di Pinto A, et al., Updated perspectives on emerging vibrios associated with human infections. Lett Appl Microbiol 2004; 39(2): 117-126.

102. Almuhaideb E, Chintapenta LK, Abbott A, et al., Assessment of Vibrio parahaemolyticus levels in oysters (Crassostrea virginica) and seawater in Delaware Bay in relation to environmental conditions and the prevalence of molecular markers to identify pathogenic Vibrio parahaemolyticus strains. PLoS One 2020; 15(12).

103. Liu W, Shen X, Liu C, et al., Vibrio parahaemolyticus in granulated ark shell clam (Tegillarca granosas): Accumulation from water and survival during cold storage and thermal process. Int J Food Sci Technol 2010; 45(4): 670-675.

104. Deepanjali A, Kumar HS, Karunasagar I, et al., Seasonal variation in abundance of total and pathogenic Vibrio parahaemolyticus bacteria in oysters along the southwest coast of India. Appl Environ Microbiol 2005; 71(7): 3575-3580.

105. Chen $\mathrm{S}$ and Ge B, Development of a toxR-based loop-mediated isothermal amplification assay for detecting Vibrio parahaemolyticus. BMC Microbiol 2010; 10(1): 41-41.

106. Croci L, Suffredini E, Cozzi L, et al., Evaluation of different polymerase chain reaction methods for the identification of Vibrio parahaemolyticus strains isolated by cultural methods. J AOAC Int 2007; 90(6): 1588-1597.

107. Daniels NA, Ray B, Easton A, et al., Emergence of a new Vibrio parahaemolyticus serotype in raw oysters: A prevention quandary. JAMA 2000; 284(12): 1541-1545.

108. Paydar M, Teh CSJ, and Thong KL, Prevalence and characterisation of potentially virulent Vibrio parahaemolyticus in seafood in Malaysia using conventional methods, PCR and REP-PCR. Food Control 2013; 32(1): 13-18.

109. Tan CW, Rukayadi Y, Hasan H, et al., Prevalence and antibiotic resistance patterns of Vibrio parahaemolyticus isolated from different types of seafood in Selangor, Malaysia. Saudi J Biol Sci 2020; 27(6): 1602-1608. 
110. Siddique AB, Moniruzzaman M, Ali S, et al., Characterization of pathogenic Vibrio parahaemolyticus isolated from fish aquaculture of the Southwest coastal area of Bangladesh. Front Microbiol 2021; 12 : 635539.

111. $\mathrm{Hu}$ Y, Li F, Zheng Y, et al., Prevalence and population analysis of Vibrio parahaemolyticus in retail aquatic products from the southern Fujian coast, China. J Food Saf 2020; 40(5).

112. Song X, Zang J, Yu W, et al., Occurrence and identification of pathogenic Vibrio contaminants in common seafood available in a chinese traditional market in Qingdao, Shandong province. Front Microbiol 2020; 11(1488).

113. Kang C-H, Shin Y, Yu H, et al., Antibiotic and heavy-metal resistance of Vibrio parahaemolyticus isolated from oysters in Korea. Mar Pollut Bull 2018; 135: 69-74.

114. Hsern Malcolm TT, Cheah YK, Radzi CWJWM, et al., Detection and quantification of pathogenic Vibrio parahaemolyticus in shellfish by using multiplex PCR and loop-mediated isothermal amplification assay. Food Control 2015; 47: 664-671.

115. Sudha S, Mridula C, Silvester R, et al., Prevalence and antibiotic resistance of pathogenic Vibrios in shellfishes from Cochin market. Indian J Geo-Mar Sci 2014.

116. Vasudevan P, Marek P, Daigle S, et al., Effect of chilling and freezing on survival of Vibrio parahaemolyticus on fish fillets J Food Saf 2002; 22(4): 209-217.

117. Cabanillas-Beltrán H, Llausás-Magaña E, Romero R, et al., Outbreak of gastroenteritis caused by the pandemic Vibrio parahaemolyticus O3 : K6 in Mexico. FEMS Microbiol Lett 2006; 265(1): 76-80.

118. Kang C-H, Shin Y, Jang S, et al., Characterization of Vibrio parahaemolyticus isolated from oysters in Korea: Resistance to various antibiotics and prevalence of virulence genes. Mar Pollut Bull 2017; 118(1-2): 261-266.

119. Li Y, Xie T, Pang R, et al., Food-borne Vibrio parahaemolyticus in China: Prevalence, antibiotic susceptibility, and genetic characterization. Front Microbiol 2020; 11: 1670-1670.

120. Christoph JH, Type III protein secretion systems in bacterial pathogens of animals and plants. Microbiol Mol Biol Rev 1998; 62(2): 379-433.

121. Gaytán MO, Martínez-Santos VI, Soto E, et al., Type three secretion system in attaching and effacing pathogens. Front Cell Infect Microbiol 2016; 6(129).

122. Wang $\mathrm{R}$, Zhong $\mathrm{Y}, \mathrm{Gu} \mathrm{X}$, et al., The pathogenesis, detection, and prevention of Vibrio parahaemolyticus. Front Microbiol 2015; 6(144).

123. Mahoney JC, Gerding MJ, Jones SH, et al., Comparison of the pathogenic potentials of environmental and clinical Vibrio parahaemolyticus strains indicates a role for temperature regulation in virulence. Appl Environ Microbiol 2010; 76(22): 7459-7465.

124. Gutierrez West CK, Klein SL, and Lovell hR, High frequency of virulence factor genes tdh, trh, and th in Vibrio parahaemolyticus strains isolated from a pristine estuary. Appl Environ Microbiol 2013; 79(7): 2247-2252.

125. Miyamoto Y, Kato T, Obara Y, et al., In vitro hemolytic characteristic of Vibrio parahaemolyticus: Its close correlation with human pathogenicity. J Bacteriol 1969; 100(2): 1147-1149.

126. Levin RE. Vibrio parahaemolyticus, a notably lethal human pathogen derived from seafood: A review of its pathogenicity, characteristics, subspecies characterization, and molecular methods of detection. Food Biotechnol 2006; 20(1): 93-128. 
127. Drawz SM and Bonomo RA, Three decades of beta-lactamase inhibitors. Clin Microbiol Rev 2010; 23(1): 160-201.

128. Dahanayake PS, Hossain S, Wickramanayake MVKS, et al., Prevalence of virulence and extendedspectrum $\beta$-lactamase (ESBL) genes harbouring Vibrio spp. isolated from cockles (Tegillarca granosa) marketed in Korea. Lett Appl Microbiol 2020; 71(1): 61-69.

129. Silvester R, Pires J, Van Boeckel TP, et al., Occurrence of $\beta$-lactam resistance genes and plasmidmediated resistance among Vibrios isolated from Southwest Coast of India. Microb Drug Resist 2019; 25(9): 1306-1315.

130. Paterson DL and Bonomo RA, Extended-spectrum beta-lactamases: A clinical update. Clin Microbiol Rev 2005; 18(4): 657-686.

131. Sheu C-C, Chang Y-T, Lin S-Y, et al., Infections caused by carbapenem-resistant Enterobacteriaceae: An update on therapeutic options. Front Microbiol 2019; 10(80).

132. Lopatek M, Wieczorek K, and Osek J, Antimicrobial resistance, virulence factors, and genetic profiles of Vibrio parahaemolyticus from seafood. Appl Environ Microbiol 2018; 84(16): e00537-18.

133. Heuer OE, Kruse H, Grave K, et al., Human health consequences of use of antimicrobial agents in aquaculture. Clin Infect Dis 2009; 49(8): 1248-1253.

134. Alanis AJ, Resistance to antibiotics: are we in the post-antibiotic era? Arch Med Res 2005; 36(6): 697705 .

135. Mayer LW, Use of plasmid profiles in epidemiologic surveillance of disease outbreaks and in tracing the transmission of antibiotic resistance. Clin Microbiol Rev 1988; 1(2): 228-243.

136. Bukowski M, Piwowarczyk R, Madry A, et al., Prevalence of antibiotic and heavy metal resistance determinants and virulence-related genetic elements in plasmids of Staphylococcus aureus. Front Microbiol 2019; 10: 805-805.

137. Han JE, Mohney LL, Tang KFJ, et al., Plasmid mediated tetracycline resistance of Vibrio parahaemolyticus associated with acute hepatopancreatic necrosis disease (AHPND) in shrimps. Aquacult Rep 2015; 2: 17-21.

138. Marti E, Variatza E, and Balcazar JL, The role of aquatic ecosystems as reservoirs of antibiotic resistance. Trends Microbiol 2013; 22(1): 36-41.

139. Munita JM and Arias CA, Mechanisms of antibiotic resistance. Microbiol Spectr 2016; 4(2): 10.1128/microbiolspec.VMBF-0016-2015.

140. Amalina NZ, Santha S, Zulperi D, et al., Prevalence, antimicrobial susceptibility and plasmid profiling of Vibrio spp. isolated from cultured groupers in Peninsular Malaysia. BMC Microbiol 2019; 19(1): 251.

141. Bennett PM, Plasmid encoded antibiotic resistance: Acquisition and transfer of antibiotic resistance genes in bacteria. Br J Pharmacol 2008; 153 Suppl 1(Suppl 1): S347-S357.

142. Meletis G, Carbapenem resistance: overview of the problem and future perspectives. Ther Adv Infect Dis 2016; 3(1): 15-21.

143. Livermore DM, Nicolau DP, Hopkins KL, et al., Carbapenem-resistant Enterobacterales, carbapenem resistant organisms, carbapenemase-producing Enterobacterales, and carbapenemase-producing organisms: Terminology past its "Sell-By Date" in an era of new antibiotics and regional carbapenemase epidemiology. Clin Infect Dis 2020; 71(7): 1776-1782. 
144. Mangat CS, Boyd D, Janecko N, et al., Characterization of VCC-1, a novel ambler class A carbapenemase from Vibrio cholerae isolated from imported retail shrimp sold in Canada. Antimicrob Agents Chemother 2016; 60(3): 181991825.

145. Letchumanan V, Chan K-G, and Lee L-H, An insight of traditional plasmid curing in Vibrio species. Front Microbiol 2015; 6: 735.

146. Misol GN, Kokkari C, and Katharios P, Biological and genomic characterization of a novel jumbo bacteriophage, vB_VhaM_pir03 with broad host lytic activity against Vibrio harveyi. Pathogens 2020; 9(12): 1051.

147. Hu Z, Chen X, Chen W, et al., Siphoviridae phage PH669 capable of lysing some strains of $\mathrm{O}_{3}$ and $\mathrm{O}_{4}$ serotypes in Vibrio parahaemolyticus. Aquacult 2021; 545: 737192.

148. Tan LT-H, Chan K, and Lee L, Application of bacteriophage in biocontrol of major foodborne bacterial pathogens. J Mol Biol Mol Imaging 2014; 1(9).

149. Dubey S, Singh A, Kumar BN, et al., Isolation and characterization of bacteriophages from inland saline aquaculture environments to control Vibrio parahaemolyticus contamination in shrimp. Indian J Microbiol 2021; 61(2): 212-217.

150. Ibrahim WNW, Leong LK, Razzak LA, et al., Virulence properties and pathogenicity of multidrugresistant Vibrio harveyi associated with luminescent vibriosis in pacific white shrimp, Penaeus vannamei. J Invertebr Pathol 2021: 107594.

151. Kowalska JD, Kazimierczak J, Sowińska PM, et al., Growing trend of fighting infections in aquaculture environment — opportunities and challenges of phage therapy. Antibiotics 2020; 9(6): 301.

152. D'Accolti M, Soffritti I, Mazzacane S, et al., Bacteriophages as a potential 360-degree pathogen control strategy. Microorganisms 2021; 9(2): 261.

153. Żaczek M, Weber-Dąbrowska B, and Górski A, Phages as a cohesive prophylactic and therapeutic approach in aquaculture systems. Antibiotics 2020; 9(9): 564.

154. Acharyya S, Patra A, and Bag PK, Evaluation of the antimicrobial activity of some medicinal plants against enteric bacteria with particular reference to multi-drug resistant Vibrio cholerae. Trop J Pharm Res 2009; 8(3).

155. Ma DS, Tan LT-H, Chan K-G, et al., Resveratrol-potential antibacterial agent against foodborne pathogens. Front Pharmacol 2018; 9: 102.

156. Lee L-H, Cheah Y-K, Sidik SM, et al., Molecular characterization of Antarctic actinobacteria and screening for antimicrobial metabolite production. World J Microb Biot 2012; 28(5): 2125-2137.

157. Azman A-S, Othman I, Fang C-M, et al., Antibacterial, anticancer and neuroprotective activities of rare Actinobacteria from mangrove forest soils. Indian J Microbiol 2017; 57(2): 177-187.

158. Lee L-H, Goh B-H, and Chan K-G, Actinobacteria: Prolific producers of bioactive metabolites. Front Microbiol 2020; 11: 1612.

159. Tan LT-H, Lee L-H, and Goh B-H, The bioprospecting of anti-Vibrio Streptomyces species: Prevalence and applications. Prog Microbes Mol Biol 2019; 2(1): a0000034.

160. Law JW-F, Letchumanan V, Tan LT-H, et al., The rising of "modern actinobacteria" era. Prog Microbes Mol Biol 2020; 3(1): a0000064.

161. Ab Mutalib N-S, Wong SH, Ser H-L, et al., Bioprospecting of microbes for valuable compounds to mankind. Prog Microbes Mol Biol 2020; 3(1): a0000088. 
162. Tan LT-H, Lee L-H, and Goh B-H, Critical review of fermentation and extraction of anti-Vibrio compounds from Streptomyces. Prog Microbes Mol Biol 2020; 3(1): a0000051.

163. Kumaran S, Uttra V, Thirunavukkarasu R, et al., Bioactive metabolites produced from Streptomyces enissocaesilis SSASC10 against fish pathogens. Biocatal Agric Biotechnol 2020; 29: 101802.

164. Phuong TV, Thanh DTN, and Diep CN, Isolation and selection of bacteria against shrimp pathogenic Vibrio parahaemolyticus from shrimp pond water on Duyen Hai district, Tra Vinh province. Eng Technol 2020; 10(1): 43-52.

165. Cristobal-Cueto P, García-Quintanilla A, Esteban J, et al., Phages in Food Industry Biocontrol and Bioremediation. Antibiotics 2021; 10(7): 786.

166. Tan LT-H, Chan K-G, Lee L-H, et al., Streptomyces bacteria as potential probiotics in aquaculture. Front Microbiol 2016; 7: 79.

167. Das S, Mondal K, and Sengupta C, Evaluation of the probiotic potential of Streptomyces antibioticus and Bacillus cereus on growth performance of freshwater catfish Heteropneustes fossilis. Aquacult Rep 2021; 20: 100752.

168. Madhana S, Kanimozhi G, and Panneerselvam A, Probiotics in Shrimp Aquaculture, in Advances in Probiotics. 2021, Elsevier. p. 309-325.

169. Butt UD, Lin N, Akhter N, et al., Overview of the latest developments in the role of probiotics, prebiotics and synbiotics in shrimp aquaculture. Fish Shellfish Immunol 2021; 114: 263-281.

170. Gopal V and Dhanasekaran D, Probiotics as a growth promotant for livestock and poultry production, in Advances in Probiotics. 2021, Elsevier. p. 349-364. 